\title{
Recent Progress of Direct Ink Writing of Electronic Components for Advanced Wearable Devices
}

\author{
Yubai Zhang, ${ }^{\dagger}{ }^{\ddagger}$ Ge Shi, ${ }^{\dagger}{ }^{\ddagger}$ Jiadong Qin, ${ }^{\dagger}$ Sean E. Lowe, ${ }^{\dagger}$ Shanqing Zhang, ${ }^{\dagger}$ Huijun Zhao, ${ }^{\dagger}$ Yu \\ Lin Zhong, ${ }^{* \dagger}$ \\ ${ }^{\dagger}$ Centre for Clean Environment and Energy, School of Environment and Science, Griffith University, Gold Coast \\ Campus, Gold Coast, QLD 4222, Australia
}

KEYWORDS: 3D printing, direct ink writing, wearable electronics, ink formulation, strain sensor

\begin{abstract}
Three-dimensional (3D) printing technology has been recognized as an emerging advanced fabrication technology in both industry and academia. Direct ink writing (DIW), a type of 3D printing technology, can build 3D structures through the deposition of custom-made inks, printing devices with complex architectures, excellent mechanical properties and enhanced functionalities. DIW can greatly facilitate the fabrication of miniaturized or flexible electronic components. These components are potentially useful for their applications in advanced wearable devices. This article highlights recent advancements in 3D direct ink written electronic components with an emphasis on their potential applications for wearable devices. The relationship among ink formulations, DIW techniques and printed devices is highlighted. In particular, the DIW-assisted fabrication of key components in wearable electronics, including power generation (nanogenerators), energy storage (e.g. lithium ion batteries) and energy consuming products (e.g. strain sensors) are reviewed in terms of performance metrics and fabrication strategies. Optimized ink preparations, evolving DIW techniques, and device designs can work synergistically to enhance the development of printed advanced wearable devices.
\end{abstract}

\section{INTRODUCTION}

In the past two decades, much effort has been devoted to wearable electronics, yielding significant achievements. ${ }^{1,2}$ Wearable electronics have been used in a wide range of applications, e.g. strain sensors, ${ }^{2,3}$ artificial skins, ${ }^{4}$ flexible touch screen, ${ }^{5}$ transistors, ${ }^{6}$ soft actuators, ${ }^{7}$ flexible piezoelectric devices ${ }^{8}$ and energy harvesting and storage devices. ${ }^{9}$ For example, physical, chemical, biological, and environmental states of the human body can be monitored by various flexible electrical sensors that can be easily mounted on human skin without discomfort. ${ }^{10}$ Moreover, with the impending arrival of the Internetof-Things, wearable energy harvesting and storage devices have attracted much attention because they could potentially provide energy for various wearable electronics. ${ }^{11,12}$

Direct ink writing (DIW) three-dimensional (3D) printing techniques have been employed in recent years to print complex 3D objects through the layer-by-layer deposition of printable inks. Typically, the process starts from a 3D model that can be translated into code used by the 3D printer. The printer can precisely manipulate the extrusion of fluidic inks through a nozzle to print the designs. ${ }^{13}$ DIW techniques have several advantages for the fabrication of wearable devices. They can typically print electronic components across multiple length scales, from sub-micrometer to millimeters, with intricate and high resolution architectures, such as 3D porous ${ }^{9}$ and hierarchical structures. ${ }^{14}$ Moreover, DIW methods can directly print electronic components without template supports, therefore enabling the design and fabrication of products with complex 3D shapes without the need for expensive tooling, dies or lithographic masks. ${ }^{15}$ In addition, DIW can print multiple components simultaneously or in quick succession, which enables new types of multi-material architectures. ${ }^{15}$

Printable inks are a key component in DIW as they determine not only the possible printable geometries, but also the internal structure and performance of resultant objects. ${ }^{16}$ In printed wearable electronics, ink materials can impart flexibility, mechanical robustness and electrical conductivity. Several nanomaterials, such as nanoparticles, ${ }^{17,}{ }^{18}$ nanotubes ${ }^{19}$ and nanowires, ${ }^{20}$ can be used in functional inks. In particular, inks based on atomically thin two dimensional (2D) materials such as graphene are strong candidates for printable, wearable devices. 2D nanomaterials can imbue printed products with extraordinary attributes, ${ }^{21}$ e.g. high electrical and thermal conductivity, ${ }^{22,}{ }^{23}$ chemical and environmental stability, ${ }^{24}$ and ultrahigh mechanical strength and flexibility. ${ }^{25}$ Apart from nanomaterials, liquid metals are another attractive class of 
materials for the formulation of functional inks for printing wearable electronics due to their intrinsic conductivity and flexibility. ${ }^{26,27}$
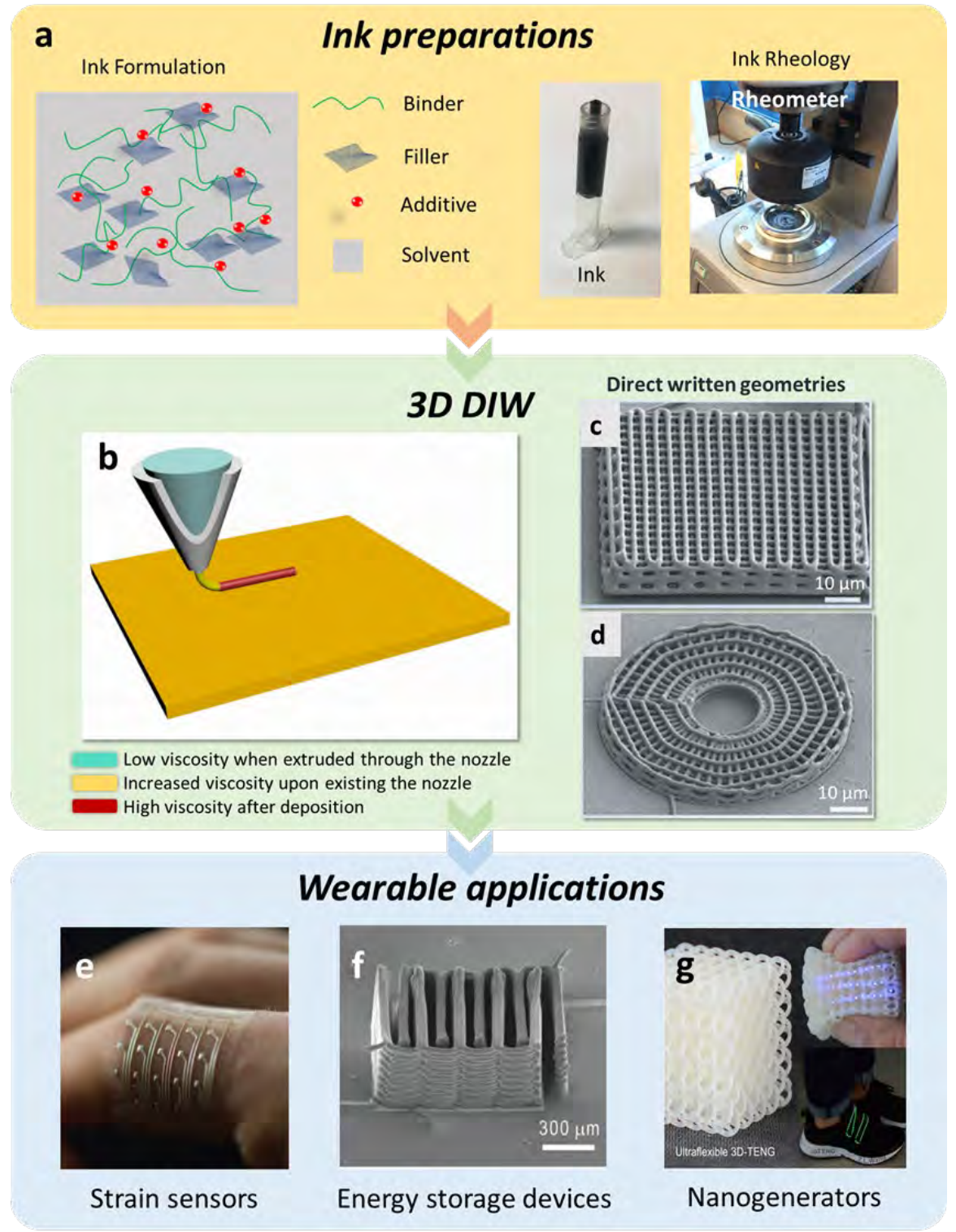

Figure 1. Overview of ink preparation and the fabrication of various wearable electronics via 3D DIW. (a) Ink preparation consists of ink formulation and rheology. The printable ink is typically formulated with fillers, binders, additives and solvents. Ink rheology can be measured using a rheometer. (b) Stable and controllable ink flow allows the formation of complex 3D assemblies, such as (c) a "face-centered tetragonal geometry" and (d) a radial array. Reproduced with permission. ${ }^{28}$ Copyright 2004, Nature Publishing Group. DIW methods enable printing a range of products, including (e) strain sensors (Reproduced with permission. ${ }^{29}$ Copyright 2017 Wiley-VCH), (f) energy storage devices, such as the interdigitated lithium ion battery (LIB) shown (Reproduced with permission. ${ }^{17}$ Copyright 2013, Wiley-VCH), and (g) nanogenerators (Reproduced with permission. ${ }^{30}$ Copyright 2018, Elsevier).

In this article, we aim to provide a comprehensive and critical review of 3D DIW for the fabrication of various wearable electronics. The basic mechanism of 3D DIW and relevant ink rheology are first described. Several notable DIW ink formulations, especially 2D-materials and liquid metals-based inks, are discussed in detail. Subsequently, we introduce several niche applications enabled by DIW, namely wearable strain sensors, energy storage devices and nanogenerators. With respect to these applications, we pay special attention to the ink preparations, printing procedures and the properties 
of the final products. In addition, examples of commercially-available 3D DIW printers used for wearable electronics are reviewed. Lastly, the current status of direct ink written applications and some prospects for future development are presented. The major purpose of this article is to elucidate the relationships among ink rheology, DIW methods and applications, thereby guiding readers to find suitable ink formulations for high-performance wearable electronics.

\section{PRINTING MECHANISM AND INK RHEOLOGY}

DIW enables the creation of complex 3D structures at the microscale level, typically via layer-by-layer assembly. DIW has demonstrated great potential for emerging applications, including photonics, ${ }^{31}$ microelectronics, ${ }^{17}$ advanced ceramics, ${ }^{32,} 33$ microfuel cells and batteries, ${ }^{17}$ sensors, ${ }^{34,35}$ and biological applications. ${ }^{32-36}$ Figure 1 shows the relationship among functional inks, 3D DIW technology and their applications in strain sensors, LIBs and nanogenerators.

Generally, the DIW process includes three steps: (1) 3D model design, (2) the generation of a path file for the printing nozzle and (3) the deposition of inks. 3D models can be generated in CAD software such as Vectary, 3D slash and Autodesk Fusion 360. Subsequently, a 2D layer-by-layer or 3D movement path file for the printing nozzle is exported to the DIW printer. For the 2D moving path, slicing software is employed to slice the 3D model layer-by-layer such that a detailed 2D map of each layer can be obtained. During the DIW printing, the nozzle moves according to the 2D paths in each layer, depositing the ink. Layer-by-layer deposition builds the 3D architecture.

In some cases, 3D structures can be printed without using a layer by layer approach. Rather, the nozzle is moved in three dimensions to directly print out 3D architectures. This technique, however, requires particular printing material strategies to hold the 3D structure after deposition. One strategy is to utilize the intrinsic properties of the ink, such as the facile oxidation and solidification of liquid metal filaments in air, to help maintain the 3D structures. ${ }^{37}$ Another strategy is to create a 3D architecture within a supportive matrix. For instance, Lewis et al. reported an embedded 3D DIW printing method for wearable strain sensors. ${ }^{38}$ In their method, the nozzle, translating through an uncured elastomer matrix, deposited conductive inks embedded in the matrix to form a 3D architecture. The printed shapes could be well maintained in the matrix after deposition.

The successful creation of 3D structures via DIW relies on the delicate preparation of inks with ideal rheological properties. Ink rheological properties describe the deformation and flow of materials during the printing process. In the printer, the flow of ink is initiated when the applied shear stress $(\tau)$ exceeds the yield point $\left(\tau_{\mathrm{y}}\right)$ of the ink, and the flow behavior is determined by the shear viscosity $(\tau)$. The relationship between shear stress, viscosity, and shear rate can be described by the HerschelBulkley model: ${ }^{39}$

$$
\tau=\eta \dot{\gamma}=\tau_{y}+K \dot{\gamma}^{n}
$$

where $\eta$ is the apparent viscosity, $\dot{\gamma}$ is the shear rate, $K$ is the viscosity parameter, and $n$ is the power law exponent.

In general, there are two types of functional DIW inks with distinct rheological behavior, low viscosity inks and shear thinning inks. Low viscosity inks can easily flow from the nozzle but need to be rapidly cured by, for example, gelation or photopolymerization after deposition to maintain the printed 3D structure. ${ }^{40,41}$ For example, low viscosity thermoplastic polyurethane (TPU) ink, with $\eta$ around $10^{1}$ to $10^{2} \mathrm{~Pa} \cdot \mathrm{s}$, has been extruded through a $200 \mu \mathrm{m}$ nozzle, behaving like a Newtonian fluid ( $\eta$ is independent of the shear rate), as shown by the blue curve in Figure 2a. ${ }^{29}$ After printing, the deposited TPU ink was cured at $80{ }^{\circ} \mathrm{C}$ within 2 h. ${ }^{29}$

Shear thinning inks, however, are more common for DIW. This type of ink becomes less viscous (smaller $\eta$ ) with increasing shear rates, $\dot{\gamma}(n<1)$. This rheological behaviour facilitates continuous and stable ink flow through a nozzle under pressure. ${ }^{42,}$ ${ }^{43}$ In recent work on DIW wearable electronics, the viscosity of inks ranges from $10^{5} \mathrm{~Pa} \cdot \mathrm{s}$ (under a low shear rate of $10^{-2} \mathrm{~s}^{-}$ $\left.{ }^{1}\right)^{17}$ to $10^{1} \mathrm{~Pa} \cdot \mathrm{s}$ (under a high shear rate of to $10^{2} \mathrm{~s}^{-1}$ ). ${ }^{44}$ Figure $2 \mathrm{a}$ (grey curve) and $2 \mathrm{~b}$ illustrate the shear thinning behavior of TPU-silver composite (AgTPU) inks designed for soft electronics, as well as graphene oxide (GO)-based electrode inks for LIBs. In the former case, the addition of silver flakes to TPU transforms the rheology of the ink from Newtonian to shear-thinning. After deposition, the inks rapidly recover their viscosity (become more gel-like) upon the removal of shear stress, allowing for freestanding 3D structures.

In addition to the viscosity, the dynamic moduli, i.e., storage modulus, $G^{\prime}$, and loss modulus, $G^{\prime \prime}$, represent the elastic and viscous components of the printable inks, respectively. The inks must have high $G^{\prime}$ as well as yield strength for shape retention of printed features. ${ }^{35,45}$ Figure 2c shows the moduli of gelated GO-based inks as a function of shear stress. The storage modulus is about ten times higher than the loss modulus under small shear stress, which means the inks are resistant 
to deformation after extrusion on the substrate. With increased shear stress, the loss modulus exceeds the storage modulus, such that the inks are deformable under high shear stress during extrusion.
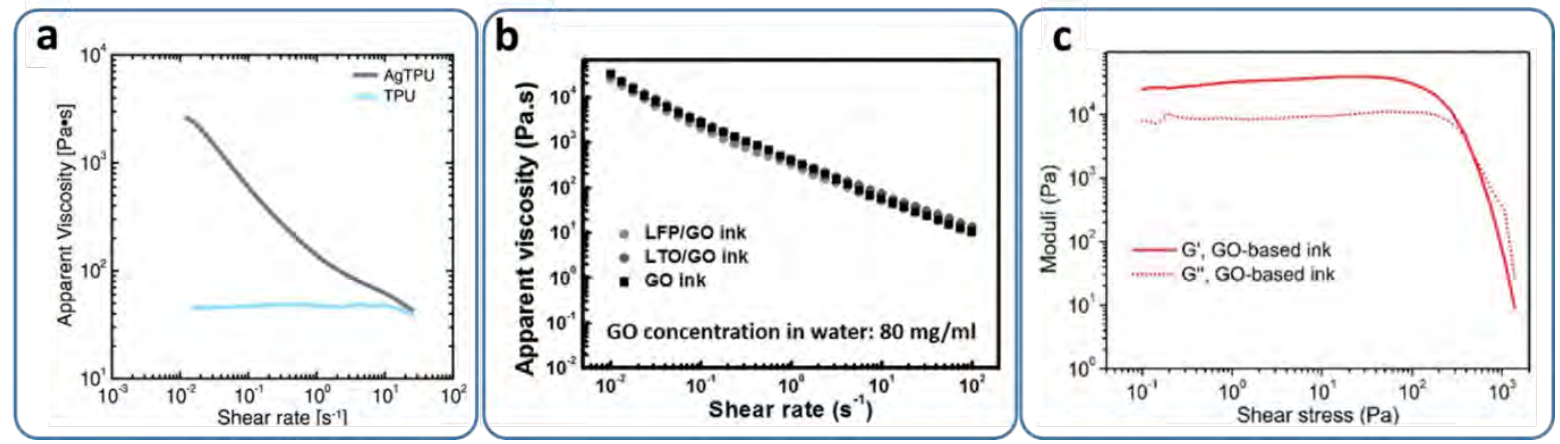

Figure 2. Apparent viscosity or shear moduli as a function of shear rate of different DIW functional inks. (a) Apparent viscosity as a function of shear rate of TPU and AgTPU inks for soft electronics. Reproduced with permission. ${ }^{29}$ Copyright 2017, Wiley-VCH. (b) Apparent viscosity as a function of shear rate for GO ink, lithium iron phosphate/graphene oxide (LFP/GO) ink, and lithium titanate oxide/graphene oxide (LTO/GO) ink for LIBs. Reproduced with permission. ${ }^{44}$ Copyright 2016, Wiley-VCH. (c) Log-log plots of $G^{\prime}$ and $G^{\prime \prime}$ versus shear stress for GO-based ink after gelation. Reproduced with permission. ${ }^{46}$ Copyright 2018 , ACS Publications.

\section{COMPOSITION OF FUNCTIONAL INK FOR DIW}

Printable inks, typically consisting of fillers, binders, additives and solvents, are a critical component in DIW. The ink components have to fit the printing process and, most importantly, deliver the desired performance in the printed devices. Table 1 gives examples of ink components for several recent 3D direct ink written wearable electronics, including strain sensors, LIBs and nanogenerators. The fillers are used to impart desired properties to the products. Emerging nanomaterialbased fillers for DIW include silver nanoparticles and GO. ${ }^{47,48}$ Binders assist in the uniform dispersion of fillers in the ink and in maintenance of the overall structural integrity of the printed ink. ${ }^{12}$ For wearable electronics, flexible polymer substrates such as PDMS, PET, etc. are widely used as the binders. Suitable solvents can optimize the viscosity, surface tension and drying rate of inks in DIW. In addition to fillers, binders and solvents, other additives can be added to facilitate DIW. Additives include substances added in small quantities which modify rheology and printability, such as humectants and surfactants. Humectants play a role of promoting the hydrophilicity of inks and reinforcing the bonding between patterned layers by maintaining residual moisture. ${ }^{17,47,49}$ The addition of surfactants can effectively reduce the surface tension of inks. ${ }^{42}$

The composition of the ink must be tuned to allow for 3D printability. Typically, colloidal gel-based inks are promising candidates for direct writing 3D architectures because their viscoelastic properties can be tailored over many orders of magnitude. They benefit from shear thinning-induced flow through nozzles and maintenance of the 3D structure after extrusion. Two points should be considered when choosing solvents and particulate fillers for DIW. Extrusion often requires significant applied pressures, and clogging can occur when the ratio between the filler's lateral dimension and the nozzle internal diameter is higher than 1:100 to $1: 150 .{ }^{15}$ The second point relates to the volatility of the solvent. Rapid solvent evaporation may prevent splaying of the extruded ink and maintenance of the shape of the printed layer. On the other hand, rapid solvent evaporation could alter the rheological properties of ink at the nozzle tip, which may cause clogging of the nozzle outlet. Solvents should be selected to achieve a balance between these effects.

The filler is particularly important as it can impart functional properties, such as conductivity, to the ink. As is apparent from Table 1, a vast array of fillers exist, including silver, metal oxide, and carbonaceous particles, rods, etc. In the following section we illustrate the use of nanofillers, particularly graphene/2D materials and liquid metals for DIW, two heavily studied classes of conductive fillers for electronics.

The morphology of 2D materials can impart a higher storage modulus without concomitant aggregation, which improves the formability of inks. In addition, the properties of 2D materials, including aspect ratio, functionalization and surface morphologies, are tunable, and this can facilitate the preparation of functional inks with suitable viscoelastic responses. Once these materials are obtained in liquid dispersions, they can be size segregated and incorporated into elastomers to form inks 
easily. ${ }^{50}$ A large number of $2 \mathrm{D}$ materials, such as $\mathrm{rGO},{ }^{51}$ black phorphorus, ${ }^{52}$ transition metal dichalcogenides, ${ }^{53}$ and MXene,$^{54}$ have been used for electronic device fabrication. However, most are utilized for inject printing or laser direct printing for 2D structured devices.

Table 1. Ink components for several 3D direct ink written wearable devices, including strain sensors, LIBs and nanogenerators.

\begin{tabular}{|c|c|c|c|c|c|}
\hline Application & Filler & Binder & Additive & Solvent & Reference \\
\hline \multirow{6}{*}{ Strain sensors } & Silver flakes & $\begin{array}{l}\text { Thermoplastic } \\
\text { polyurethane } \\
\text { (Elastollan Soft } \\
\text { 35A) }\end{array}$ & $\mathrm{n} / \mathrm{a}$ & $\begin{array}{l}\mathrm{N}, \mathrm{N}- \\
\text { dimethylformami } \\
\text { de (DMF), } \\
\text { tetrahydrofuran } \\
\text { (THF) }\end{array}$ & 29 \\
\hline & $\begin{array}{l}\text { Silver } \\
\text { nanoparticles }\end{array}$ & $\begin{array}{l}\text { Silicone rubber } \\
\text { (Dragon skin 10) }\end{array}$ & $\begin{array}{l}\text { Slo-Jo Cure } \\
\text { Retarder (0.5 wt\%) }\end{array}$ & DCM (10 wt\%) & 3 \\
\hline & Copper nanowires & $\mathrm{n} / \mathrm{a}$ & $\begin{array}{l}\text { Hydroxypropyl } \\
\text { cellulose }\end{array}$ & Water & 55 \\
\hline & Carbon black & $\begin{array}{l}\text { Thermoplastic } \\
\text { polyurethane }\end{array}$ & $\begin{array}{l}\text { Nanoclay (Cloisite } \\
\mathrm{Na}^{+} \text {) }\end{array}$ & $\mathrm{DMF}$ & 56 \\
\hline & Carbon black & $\begin{array}{l}\text { Thermoplastic } \\
\text { polyurethane }\end{array}$ & $\begin{array}{l}\text { Sodium chloride } \\
\text { microparticles }\end{array}$ & $\mathrm{DMF}$ & 57 \\
\hline & $\begin{array}{l}\text { Eutectic Gallium- } \\
\text { Indium alloy }\end{array}$ & $\mathrm{n} / \mathrm{a}$ & $\mathrm{n} / \mathrm{a}$ & $\mathrm{n} / \mathrm{a}$ & 58 \\
\hline \multirow{7}{*}{ LIBs } & $\begin{array}{l}\mathrm{LiMn}_{2} \mathrm{O}_{4} \\
\text { carbon black }\end{array}$ & $\begin{array}{l}\text { Polyvinylidene } \\
\text { fluoride } \\
\text { (PVDF) }\end{array}$ & $\mathrm{n} / \mathrm{a}$ & NMP & 59 \\
\hline & $\begin{array}{l}\mathrm{Li}_{4} \mathrm{Ti}_{5} \mathrm{O}_{12} \\
\mathrm{LiFePO}_{4}\end{array}$ & $\begin{array}{l}\text { Aqueous } \\
\text { hydroxyethyl } \\
\text { cellulose }\end{array}$ & $\begin{array}{l}\text { Glycerol/ethylene } \\
\text { glycol }\end{array}$ & DI water & 17 \\
\hline & $\begin{array}{l}\mathrm{LiFePO}_{4} / \mathrm{Li}_{4} \mathrm{Ti}_{5} \mathrm{O}_{1} \\
\text { /GO }\end{array}$ & $\mathrm{n} / \mathrm{a}$ & $\mathrm{n} / \mathrm{a}$ & DI water & \multirow{2}{*}{44} \\
\hline & $\mathrm{Al}_{2} \mathrm{O}_{3}$ & $\begin{array}{l}\text { PVDF-co- } \\
\text { hexafluoropropylen } \\
\text { e (HFP) }\end{array}$ & $\mathrm{n} / \mathrm{a}$ & NMP & \\
\hline & $\begin{array}{l}\mathrm{Li}_{4} \mathrm{Ti}_{5} \mathrm{O}_{12} \mathrm{LiCoO}_{2} \\
\mathrm{LiFePO}_{4} \\
\text { graphite/carbon } \\
\text { black/carbon } \\
\text { nanofibres } \\
\text { (CNFs) }\end{array}$ & PVDF & $\mathrm{n} / \mathrm{a}$ & NMP & 60 \\
\hline & $\begin{array}{l}\mathrm{LiMn}_{0.21} \mathrm{Fe}_{0.79} \mathrm{PO}_{4} \\
\text { @carbon black }\end{array}$ & PVDF & $\mathrm{n} / \mathrm{a}$ & NMP & 23 \\
\hline & $\begin{array}{l}\mathrm{LiFePO}_{4} / \mathrm{Li}_{4} \mathrm{Ti}_{5} \mathrm{O}_{1} \\
{ }_{2} / \mathrm{CNFs}_{2} / \mathrm{Al}_{2} \mathrm{O}_{3}\end{array}$ & PVDF & $\mathrm{n} / \mathrm{a}$ & NMP/glycerol & 61 \\
\hline
\end{tabular}




\begin{tabular}{|l|l|l|l|l|l|}
\hline \multirow{5}{*}{ Nanogenerators } & $\begin{array}{l}\text { Acrylonitrile } \\
\text { butadiene } \\
\text { styrene/acrylate } \\
\text { oligomer }\end{array}$ & n/a & $\begin{array}{l}\text { Photoinitiator/ } \\
\text { reactive diluents }\end{array}$ & Acroleic acid & 30 \\
\cline { 2 - 6 } & Acrylate oligomer & $\mathrm{n} / \mathrm{a}$ & $\begin{array}{l}\text { Photoinitiator/ } \\
\text { reactive diluents }\end{array}$ & Acroleic acid & n/a \\
\cline { 2 - 6 } & $\begin{array}{l}\text { PDM elastomer } \\
\text { (Dow Corning } \\
737 \text { neutral cure } \\
\text { sealant, Dow } \\
\text { Corning) }\end{array}$ & $\mathrm{n} / \mathrm{a}$ & n/a & 62 \\
\hline
\end{tabular}

Graphene and its derivatives have particularly seen extensive application in 3D DIW for electronics. Graphene is one of the best known 2D materials, with high light transmittance, ${ }^{63}$ large surface area $\left(2630 \mathrm{~m}^{2} \mathrm{~g}^{-1}\right),{ }^{64}, 65$ high Young's modulus (1 TPa), ${ }^{66}$ and excellent electron mobility $\left(200,000 \mathrm{~cm}^{2} \mathrm{~V}^{-1} \mathrm{~s}^{-1}\right)^{64}$ and a variety of potentially cost effective synthetic routes. ${ }^{67-}$ ${ }^{72}$ Graphene inks have been formulated with additives to impart shear thinning viscosity and a modest storage modulus to maintain the printed 3D architecture. ${ }^{25}, 73$ For instance, a solid mixture containing polylactide-co-glycolide copolymer (40 vol\%) and graphene (60 vol\%) was mixed with a solvent mixture of dichloromethane (DCM), 2-Butoxyethanol (a surfactant), and dibutyl phthalate (a platicizer) in a 10:2:1 mass ratio. ${ }^{25}$ Rapid evaporation of the DCM solvent following extrusion was key to producing self-supporting fibers that did not significantly deform following DIW. The less volatile residual solvents, 2-butoxyethanol and DBP, helped impart a small amount of fluidity to the printed structure, such that the printed layers had better connectivity. This resulted in a coherent, free-standing 3D lattice (Figure 3a and b). In a second example, ethyleneglycol butylether (EGB) and a mixture of DBP/polyvinyl butyral (PVB) were used as additives in a graphene DIW ink with an ethanol solvent. ${ }^{74}$ The EGB acts as a surfactant to modify graphene via $\pi-\pi$ interactions, so that the graphene can be uniformly dispersed in ethanol.

A limitation for graphene in terms of DIW inks is that it can only be well dispersed in a few solvents, including benzyl benzoate, 1-methyl-2-pyrrolidone (NMP), g-butyrolactone (GBL), N,N-dimethylacetamide (DMA), N-vinyl-2-pyrrolidone (NVP), and DMF. However, the relatively high boiling temperature $\left(150-300{ }^{\circ} \mathrm{C}\right)$ of such solvents mean they are difficult to remove during solvent evaporation or curing of deposited inks. In contrast to pristine graphene, GO is somewhat more suitable for printable inks. This is because hydrophilic GO can disperse uniformly in multiple green solvents, such as water and alcohols, which is beneficial to the development of eco-friendly DIW technology. ${ }^{75}$

The viscosity of GO ink can be easily tailored by changing the GO concentration, producing a liquid-like solution ( 1 $\mathrm{mg} / \mathrm{ml})$ or a gel like ink ( 100 mg/ml). For example, Wallace et al. studied the relationship between the concentration of GO with lateral dimensions of $50-250 \mu \mathrm{m}$ and the rheological properties of GO aqueous dispersions. ${ }^{76}$ As shown in Figure 3a, the viscous (loss) modulus $G^{\prime \prime}$ was larger than the elastic (storage) $G^{\prime}$ modulus when the concentration was lower than $0.25 \mathrm{mg} / \mathrm{ml}$. When the $\mathrm{GO}$ concentration was up to $0.75 \mathrm{mg} / \mathrm{ml}$ (Figure 3b), $G^{\prime \prime}$ was similar to $G^{\prime}$, indicating the crowding of GO sheets and transition from a viscous liquid to soft viscoelastic solid. At higher concentrations up to $2.5 \mathrm{mg} / \mathrm{ml}$ (Figure 3c), $G^{\prime}$ became higher than $G^{\prime \prime}$. At such concentrations, GO sheets started to form a tenuous network architecture and the dispersion started to exhibit nematic-liquid-crystal-like properties. As the concentration increased to $4.5 \mathrm{mg} / \mathrm{ml}$ (Figure 3d), the $G^{\prime}$ values reach 15 77 Pa and become much higher than $G^{\prime}$, indicating the dispersion behavior became similar to that of a polymer network. At an even higher concentration of $13.35 \mathrm{mg} / \mathrm{ml}$, $G^{\prime}$ was considerably higher than $G^{\prime \prime}$, and the GO dispersion exhibited a viscoelastic liquid-crystal-gel-like condition. The high elasticity of GO viscoelastic gel means it can exhibit shear thinning effects during extrusion and retain extruded 3D structures. ${ }^{77}$ 

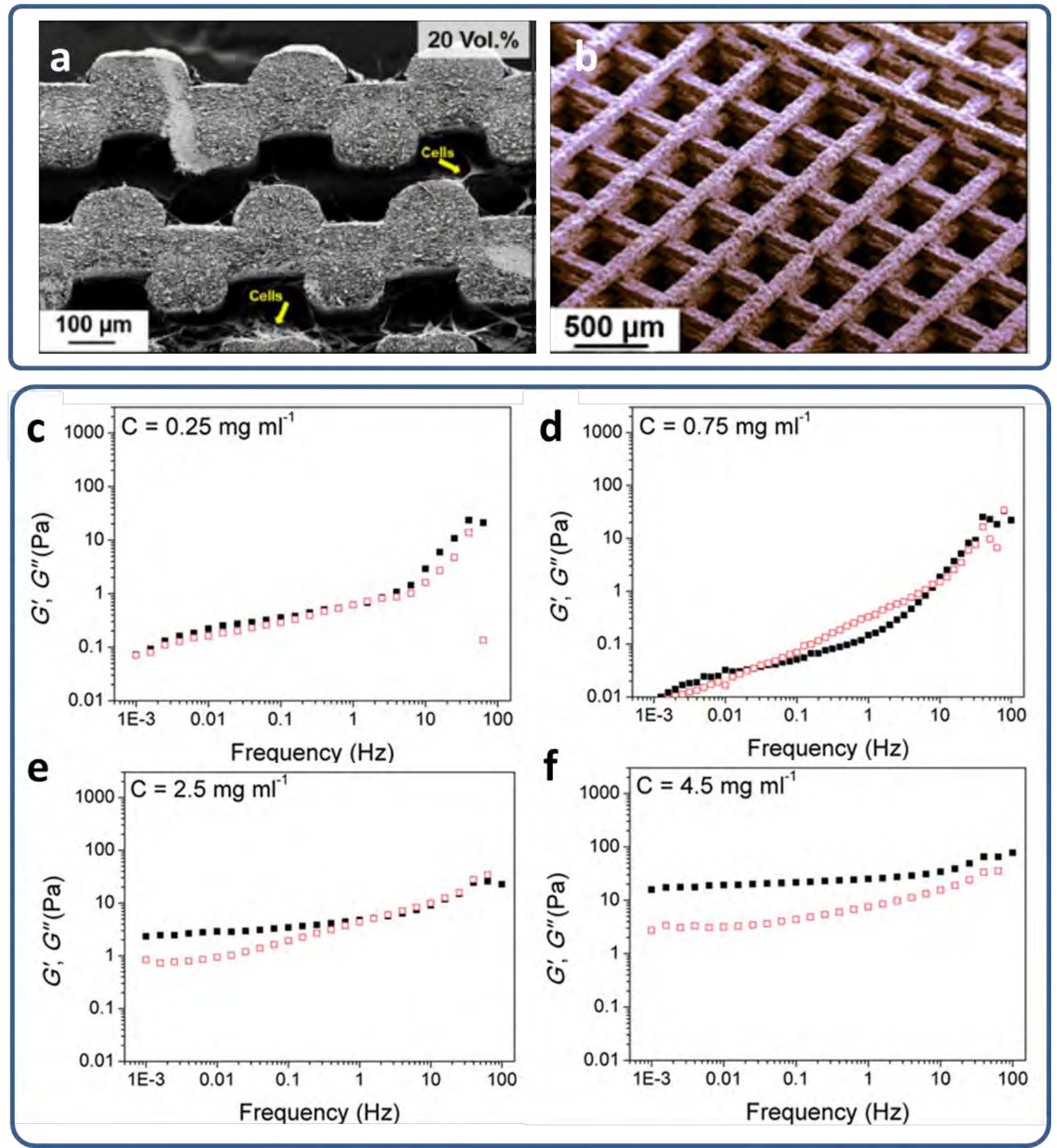

Figure 3. SEM micrographs of (a) a cross-section of layers in a graphene scaffold and (b) a 3D graphene scaffold. ${ }^{25}$ Copyright 2015, American Chemical Society. (c-f) Relationship between GO concentration and rheological properties of GO aqueous dispersions. Storage and loss moduli of GO suspensions (filled squares and open squares, respectively) as a function of the frequency of dynamic stress sweeps at different strain and concentration. Reproduced with permission. ${ }^{76}$ Copyright 2014 , The Royal Society of Chemistry.

Nanoholes can be introduced into GO sheets by removing defective carbons from the basal planes of GO, and such holey GO can be used as a nanofiller in ink. The nanoholes can serve as the conductive channels for transporting ions, and hence these holey GO sheets are employed in electrochemical systems to promote charge transport. As shown in Figure 4a, holey graphene, which was produced by heating commercial graphene powder at $430{ }^{\circ} \mathrm{C}$ for 10 hours in air, was utilized as a 
starting material for further oxidation in a mixture of sulfuric acid and potassium permanganate. ${ }^{24}$ After 5 hours reaction and washing, the GO dispersion was freeze-dried and then re-dispersed into DI water to form the ink. This aqueous holey GO ink was loaded into a syringe with a $203.2 \mu \mathrm{m}$ tip to print a hierarchical porous GO mesh (Figure 4b).

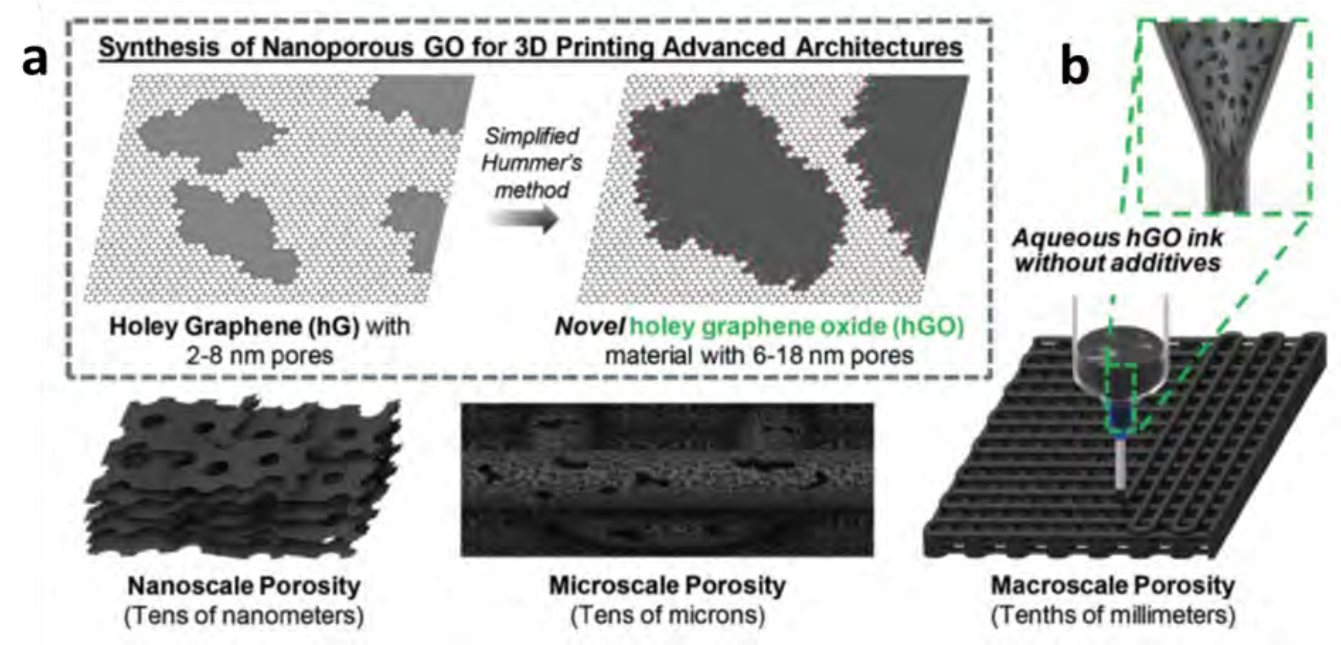

Figure 4. (a) Synthesis process for holey GO (hGO) and (b) the process for printing aqueous and additive-free hGO ink into complex 3D architectures with hierarchical porosity (macroscale $\rightarrow$ nanoscale). Reproduced with permission. ${ }^{24}$ Copyright 2018, WileyVCH.

Metals that are liquid at room temperature are also exploited in conductive inks for DIW of flexible electronics. Gallium and its alloys, such as eutectic gallium-indium (eGaIn) and gallium-indium-tin (Galinstan), are some of the most commonly used liquid metals for 3D printing of stretchable devices due to their low toxicity, low resistivity $\left(\approx 29 \times 10^{-6} \Omega \cdot \mathrm{cm}\right)$, ${ }^{78}$ low viscosity $(\approx 2.4 \mathrm{mPa} \cdot \mathrm{s}),{ }^{79}$ low melting temperature (Ga: $29.8^{\circ} \mathrm{C}$, eGaIn: $15.7{ }^{\circ} \mathrm{C}$ and Galinstan: $\left.11{ }^{\circ} \mathrm{C}\right)$ and ultra-high extensibility. ${ }^{80,81}$ In particular, Ga-based alloys are prone to form an oxide skin upon exposure to ambient air. This oxide layer not only promotes the adhesion of liquid metals to the substrate but can also help retain complicated 3D printed shapes. ${ }^{82}$ All these features allow the feasible patterning of the materials into arbitrary configurations for various flexible electronics. ${ }^{83,84}$ For example, Boley et al. fabricated a novel strain gauge where a liquid metal conducting interconnect was direct written onto a PDMS substrate. The printing setup and the repeatability of the process are shown in Figure $5 \mathrm{a}-\mathrm{d}$. ${ }^{85}$

However, DIW of Ga-based alloys and other liquid metals is limited by their high surface tension at room temperature. This can cause the coalescence of liquid metal droplets, the interruption of ink flow from the nozzle, ${ }^{83,86}$ and difficulty in printing vertical structures. ${ }^{42}$ To improve the 3D printability of liquid metals, Daalkhaijav et al. introduced nickel particles into eGaIn by high intensity sonication to form a new mixture with increased viscosity and elasticity. Their method can enhance the wettability of the liquid metal ink and better retain printed shapes without the ink coalescing, which helps printing of vertical structures (Figure $5 \mathrm{e}-\mathrm{f}){ }^{42}$

Recently, carbon nanotube (CNT)/liquid metal composite ink was used for DIW 3D interconnections. ${ }^{37}$ To fabricate homogenous composite ink for high-resolution printing, CNTs were coated with Pt because of the affinity of Pt to the liquid metal, as shown in Figure 5g and h. Figure 5i shows the morphology of the DIW 3D arc interconnections. The incorporation of well dispersed CNTs in the liquid metal matrix improves the liquid metal's mechanical strength. 

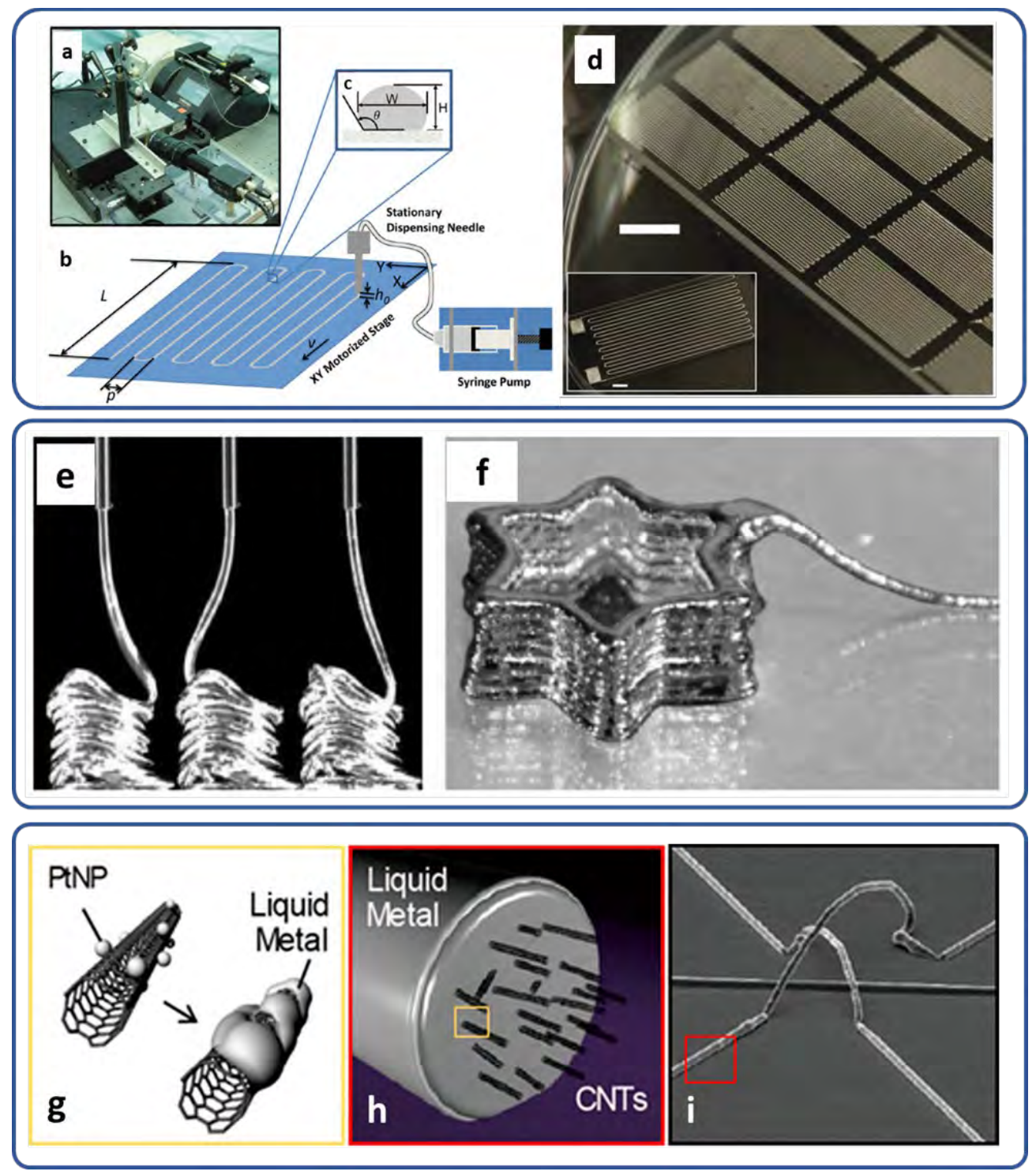

Figure 5. DIW systems for liquid metal-based products. (a) Photograph of a DIW instrument and (b) the DIW system writing a winding pattern ( $\mathrm{L}$ is the line length and $\mathrm{p}$ is spacing between lines) with a writing speed $\mathrm{v}$ ( $\mathrm{h}_{0}$ refers to the needle offset from the build platform). The flow rate is controlled by a syringe pump. (c) Cross-sectional view of a written trace of liquid metal. (d) The direct written strain gauge devices on glass. Scale bar is $5 \mathrm{~mm}$ in length. Reproduced with permission. ${ }^{85}$ Copyright 2014 , WileyVCH. (e) and (f) Photos of printing liquid metal paste in the vertical direction, forming a 3D star structure with an overhanging filament. Reproduced with permission. ${ }^{42}$ Copyright 2018, Wiley-VCH. (g) Preparation of Pt-decorated CNT/liquid metal composites. (h) Cross-section of a CNT/liquid metal filament. (i) SEM image of direct written CNT/liquid metal 3D structure. Reproduced with permission. ${ }^{37}$ Copyright 2019, ACS Publications.

\section{APPLICATIONS}

DIW has been applied to a range of electronic components for potential wearable devices, including microelectrodes, ${ }^{47}$ strain sensors, ${ }^{85}$ soft robotics and biomedical devices, ${ }^{29}$ stretchable wires, ${ }^{87}$ stretchable circuits, ${ }^{88}$ supercapacitors, ${ }^{89}$ and piezoelectric nanogenerators. ${ }^{8}$ In particular, there has been a great deal of research interest in the DIW literature in strain sensors, LIBs, and nanogenerators. 


\section{Strain sensors}

Wearable strain sensors have been applied in human motion detectors, ${ }^{90}$ human-machine interface sensors, ${ }^{91}$ and healthmonitoring devices. ${ }^{92}$ The wearable strain sensors should be lightweight and portable, ${ }^{93}$ and also meet several key requirements, including the ability to measure large strain (> 20\%) without failure, high signal-to-noise ratio, large gauge factor ( $>10)$ in order to perceive strain precisely and fast response time ( $<30 \mathrm{~ms})$ to ensure timely signal acquisition. ${ }^{94,95}$

Depending on the sensing mechanisms, strain sensors can be classified as either piezopotential or resistive. ${ }^{96}$ A typical piezopotential sensor is actually a capacitor which consists of electrolyte and two electrodes to generate capacitance $(C)$ : $^{97}$

$$
C=\varepsilon A / d
$$

where $\varepsilon$ is the dielectric constant, and $A$ and $d$ are the area and the distance between the two electrodes, respectively. When strain is applied to the sensor, changes in $A$ and $d$ will result in a piezopotential difference.

In contrast, a resistive strain sensors is based on a disconnection mechanism in the conductive materials in the sensor component. ${ }^{97,} 98$ When the strain is applied, structural deformation of sensor materials leads to a resistance change. The relationship between strain and resistance change is measured with piezoresistivity and summarized by the gauge factor $(G F)$ :

$$
G F=\left(\Delta R / R_{o}\right) / \varepsilon
$$

where $\Delta R$ is the resistance change with strain, $R_{o}$ is the resistance prior to straining, and $\varepsilon$ is the applied strain. The piezoresistivity is mainly affected by three factors: 1) tunneling resistance change between two adjacent conductors where electrons can pass through a certain distance of 1-3 nm via quantum tunneling, 2) geometrical changes of the sensor component, such as elongation with stretching and 3) piezoresistivity of individual conducting particles due to the evolution of microcracks or connection between nanomaterials upon loading. ${ }^{99}$

Recently, novel strategies have been developed to couple nanomaterials-based sensors with flexible and stretchable polymers which can be attached to human skin. ${ }^{99}$ Among these strategies, DIW has provided new opportunities for the fabrication of wearable devices with topological conformity, interwoven 3D geometries and programmable integration of multiple materials and functionalities. ${ }^{100}$ For instance, in 2017, Valentine et al. reported the fabrication of wearable strain sensors using DIW of a thermoplastic polyurethane/silver flake composite ink (AgTPU). ${ }^{29}$ Functional ink was prepared by mixing silver flakes (2-5 $\mu$ m diameter) and TPU in DMF. ${ }^{29}$ The addition of silver flakes imparted conductivity to the ink. The conductivity was proportional to the volume fraction of silver flakes, following a power-law theory for a percolation network. The power-law could be expressed as:

$$
\sigma=\sigma_{0}\left(V_{f}-V_{c}\right)^{s}
$$

where $\sigma$ is the conductivity of the ink composite, $\sigma_{0}, V_{f}$ and $V_{c}$ are the bulk conductivity, volume fraction, and critical percolation threshold of the silver flakes, respectively, and $s$ is the power law exponent. The Ag/TPU composite with 36 vol\% silver flakes and percolation threshold of $\sim 17 \%$ was utilized as the conductive ink to fabricate strain sensors. DIW was then used to successively print an insulating TPU matrix with pure TPU ink and then the conductive traces with the conductive ink to form a soft sensor array (as shown Figure 6a-c). Furthermore, an advanced wearable device was fabricated using this sensor array combined with microcontrollers (Figure 6d). The sensor collects strain data from elbow joint motion, and the microcontroller transmits the strain readout to five LED indicators in real time (Figure 6e-f). This work is a good example of wearable electronics written using conductive composite inks. The use of large-sized silver flakes (up to $5 \mu \mathrm{m}$ ), however, would limit the attainable printing resolution. The poor gauge factor of the resistive strain sensor (GF=13.3) is likely due to the very high concentration of silver flakes (36 vol.\%). 


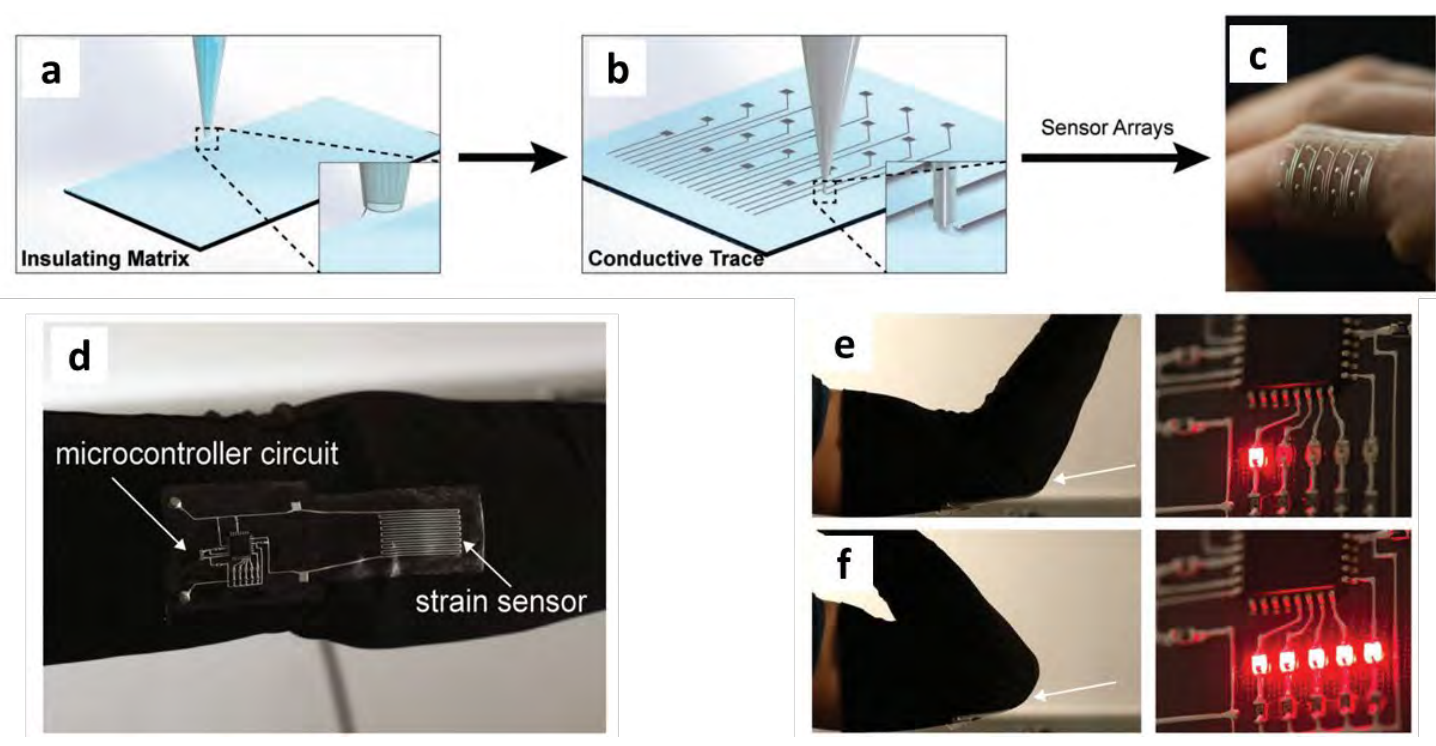

Figure 6. DIW of a TPU/silver flake composite for wearable strain sensors. (a-c) the DIW of a TPU matrix and conductive silver filler and (d) images of a textile-mounted, printed strain sensor system with microcontroller circuit, and (e and f) the corresponding LED readout at different joint bending angles. Reproduced with permission. ${ }^{29}$ Copyright 2017 Wiley-VCH.

A more sensitive stretchable tactile sensor was reported by Guo et al. ${ }^{3}$ They made use of silver nanoparticles to prepare conductive inks. A multi-material DIW method was utilized to print the tactile sensors composed of a base layer, a spiral sensor component, two electrodes, an isolating layer and a supporting component, as illustrated in Figure $7 \mathrm{a}-\mathrm{c}$. The sensor was printed using a unique layer-by-layer deposition method with different materials (Figure 7d). The concentration of silver nanoparticles in the silver/silicone composite ink varied with different printing parts. For the sensor layer, the ink consisted of 68 wt.\% silver, which was close to the percolation threshold concentration (67.45 wt.\%), and hence the printed part was sensitive to applied pressure. In contrast, the two electrodes were printed with a 75 wt.\% silver composite ink. In this component, there was a trade-off between high conductivity and stretchability in terms of the silver volume concentration. This advanced sensor, with a high gauge factor of $\sim 180$, can be used to monitor finger bending and pulse rate. The amplitude of the output signal varied with pressing forces. The sensor produced an absolute resistance of $1.14 \mathrm{k} \Omega$ at $\sim 100 \mathrm{kPa}$ and decreasing to $95 \Omega$ at $\sim 400 \mathrm{kPa}$. Upon increasing the finger pressure from $\sim 100 \mathrm{kPa}$ to $\sim 400 \mathrm{kPa}$, the responded current change correspondingly rises from $\sim 5000 \%$ to $\sim 8000 \%$ with respect to the initial state, respectively.

In strain sensors, piezoresistivity is based on the extent of electrical resistance change when mechanical stimulus is applied. The electrical resistance change is generated by the motion and deformation of conductive nanofillers inside the matrix during loading. In the context of DIW strain sensors, at least three strategies have been applied to increase the extent of electrical resistance change during loading (improving the sensitivity). Firstly, nano- and micro-scale porous structures may be introduced into the sensing component. Sensing components with porous or gap morphologies can exhibit very high sensitivity because the contact area between the pores or gaps can be significantly altered under slight deformation. ${ }^{101}$ Porous structures have been created by incorporating salts particles, such as sodium chloride, ${ }^{57}$ into the ink. After printing and curing, the salt particles are removed by immersing the device into solvents. A strain sensor developed with this technique consisted of micro-pores $(20-100 \mu \mathrm{m})$ and nano-pores $(100-500 \mathrm{~nm})$ and exhibited a high pressure sensitivity of $5.54 \mathrm{kPa}^{-1}$ in the low-pressure range $(<10 \mathrm{kPa}) .^{57}$

Secondly, making the nanofiller concentration near the percolation threshold can increase the sensitivity. At the percolation threshold, most of the nanofillers are in loose contact with one another. ${ }^{102}$ Without any load, the nanofiller particles are separated enough to guarantee only slight contact. Under loading, most the particles begin to touch each other more intimately, decreasing resistance significantly. 

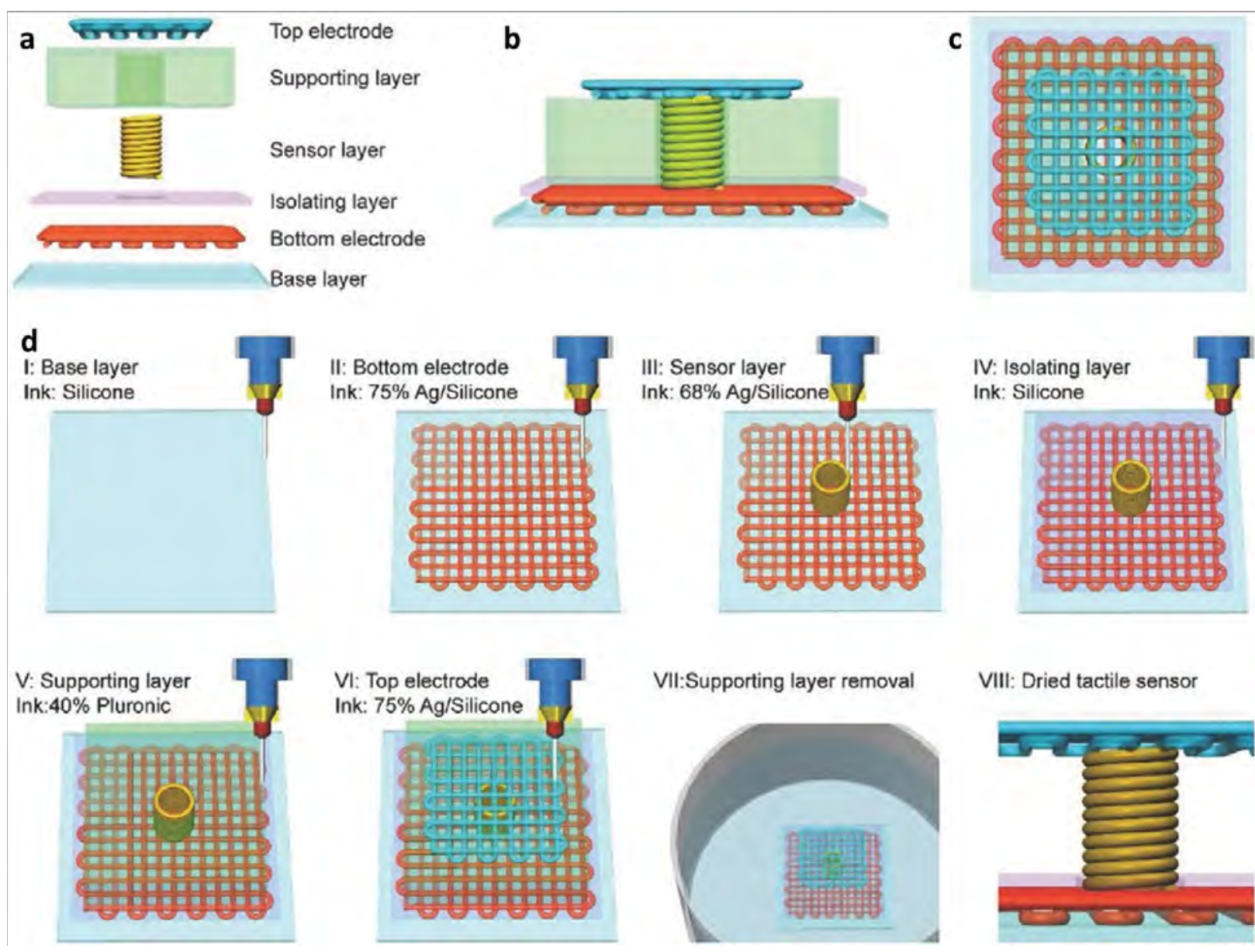

VIII: Dried tactile sensor

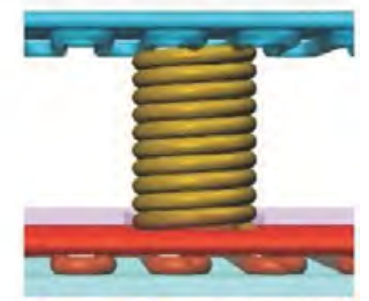

Figure 7. Silver-nanoparticle-based strain sensor design and DIW procedures. (a) Tactile sensor consisting of a base layer, two electrodes, an isolating layer, a sensor component, and a supporting layer. (b) Side and (c) top view of the tactile sensor. (d) DIW of different components of the strain sensor. Reproduced with permission. ${ }^{3}$ Copyright 2017, Wiley-VCH.

Thirdly, utilizing nano-scale conductive fillers can also increase the sensitivity. At the same volume fraction, nano-sized conductive fillers possess higher surface to volume ratio and lower particle to particle distance than micro-sized conductive fillers. ${ }^{103,104}$ Therefore, nano-sized conductive fillers can create conductive networks at lower volume fractions and provide larger contact areas within the conductive network. Upon loading, the conductive network can produce higher electrical resistance change.

In spite of the encouraging progress made, direct ink written strain sensors still require further improvement. Most strain sensors are limited by a limited range of measurable resistance (marked by an exponentially increasing resistance after a certain strain point is reached). This issue might be solved by using hybrid materials, such as a mixture of conductive nanotubes/nanowires, 2D materials or polymers. For instance, incorporation of GO sheets into an AgNW network produced a sensing component having a linear resistance response throughout a greater strain range. ${ }^{105,106}$ Under strain loading, minor microstructural deformations occured in the GO sheets, resulting in piezoresistivity. AgNWs, however, could maintain the electrical connection such that the resistance of the whole sensing component was increased progressively and linearly with strain.

In addition, it is necessary to minimize the delay in response time, which usually originates from poor strain transfer from the substrate to the sensor. The response time delay can be reduced by applying adhesive or otherwise achieving robust and conformal interactions between the substrate and the sensor. Several groups have developed biomimetic dry adhesives inspired by, for example, geckos toes ${ }^{107}$ or cephalopod skin. ${ }^{108}$ These types of materials could potentially be integrated with DIW sensors in future work to improve adhesion to human skin. 


\section{Lithium ion batteries}

Rechargeable LIBs are one of the most common energy storage devices due to their high energy and power density. ${ }^{109-111}$ DIW printable and customizable LIBs could be advantageous for integration into flexible electronics or soft robotics. ${ }^{59,112-}$ ${ }^{114}$ DIW is particularly useful for the assembly of LIBs as the printed LIBs can be directly integrated onto various substrates. The dimensions and geometries of electrodes can be easily controlled by tuning the printing speed, nozzle size and extrusion pressure in DIW methods. ${ }^{23}$ Versatile DIW techniques open up possibilities for novel design and facile fabrication of LIBs embedded in various wearable devices. The past few years have witnessed dramatic progress in printed LIBs fabricated by DIW. Generally, work on direct ink written LIBs focusses on the battery configuration as well as the battery components (electrodes, electrolytes and separators).
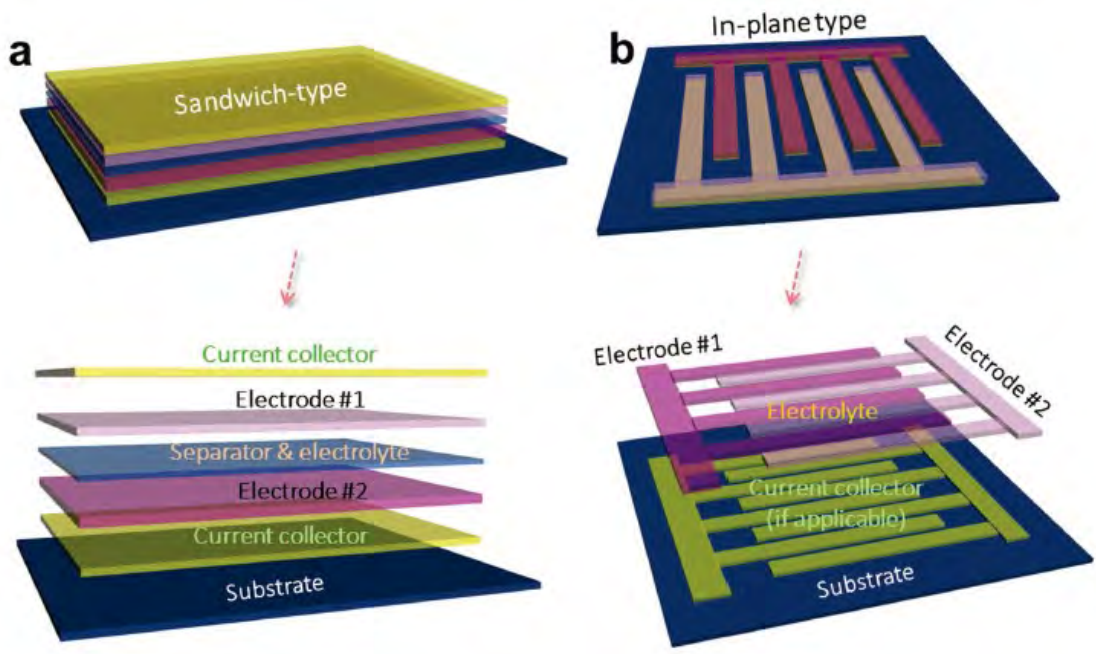

Figure 8. LIBs with sandwich-type (a) or interdigitated (b) structure. Reproduced with permission. ${ }^{115}$ Copyright 2017, Wiley-VCH.

Typically, in conventional LIBs, individual battery components, stacked layer-by-layer, are placed in a different plane (Figure 8a). In contrast to this sandwich-type LIB, interdigitated LIBs feature the patterning of two electrodes in the same plane. In this in-plane type LIB, the anode and cathode are grouped in an interdigitated configuration, as shown in Figure 8b. This special architecture can maximize the energy density per unit volume, which is especially suitable for microelectronics ${ }^{116}$ and biomedical devices. ${ }^{117}$ In 2013, Kun et al. first reported fabrication of micro-interdigitated LIBs via DIW as shown in Figure 9a-b. ${ }^{17}$ In their method, a lithium iron phosphate (LFP) cathode and lithium titanate (LTO) anode were direct written using the electrode printing inks. The inks were comprised of LFP or LTO as functional nanofillers, deionized water, ethylene glycol and glycerol as the solvent and cellulose as the binder. In the final step, the gap between the printed electrodes was filled with liquid electrolyte $\left(1 \mathrm{M} \mathrm{LiClO}_{4}\right.$ in a 1:1 ratio of ethylene carbonate:dimethyl carbonate by volume) before packaging with poly(methyl methacrylate) (PMMA) and sealing with PDMS gel (Figure 9c-d). At the current of $1 \mathrm{C}$, the areal capacity of this 8-layer interdigitated LIBs could reach $\sim 1.5 \mathrm{mAh} \mathrm{cm}^{-2}$ (Figure 9e) and was stable for up to 30 cycles (Figure 9f). It should be noted that although this is the first example of DIW of LIBs, integration into wearable devices remains a challenge because of the presence of liquid electrolyte; the use of liquid electrolyte carries the risk of leakage and swelling. 

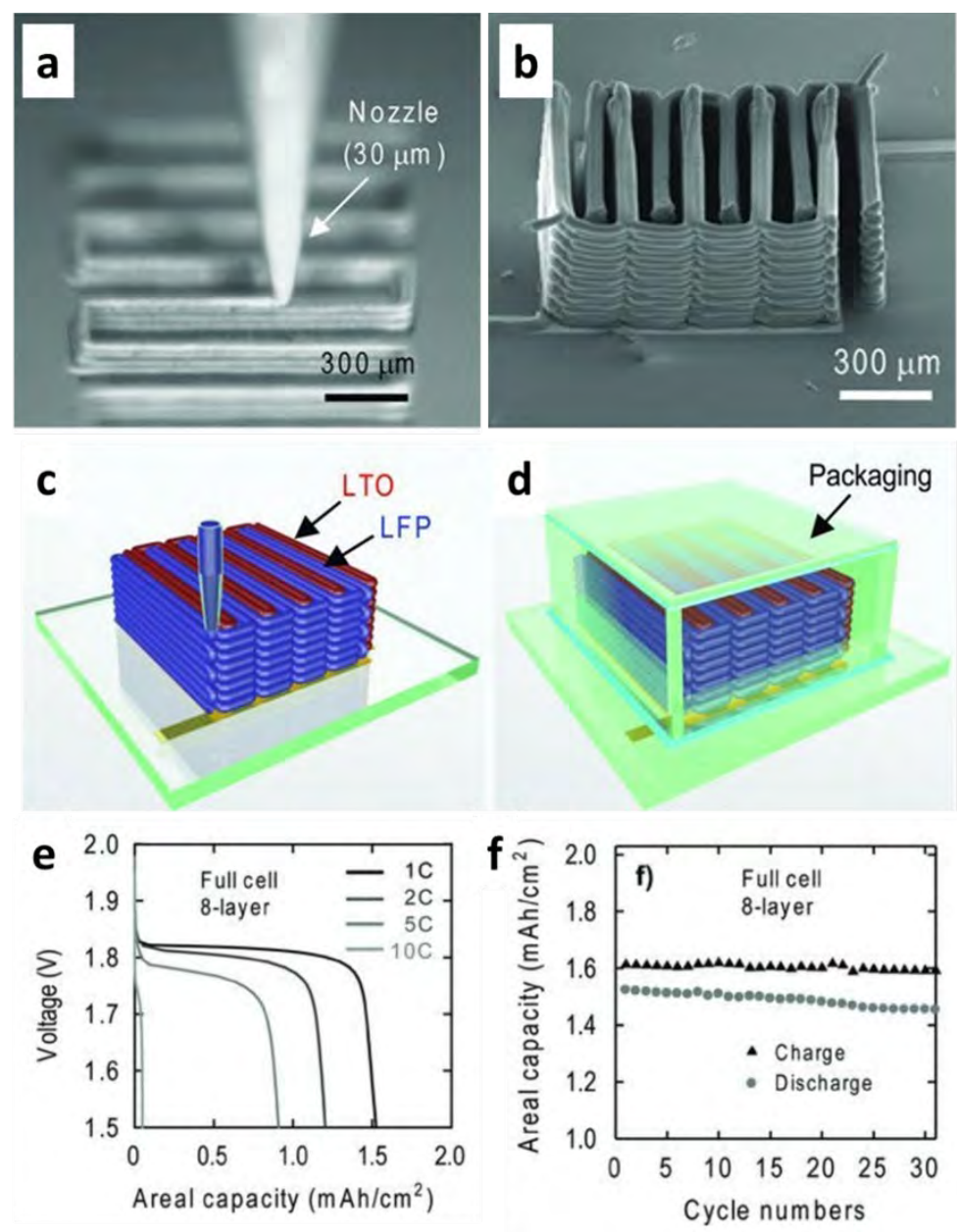

Figure 9. The architecture, electrochemical performance and assembly process of micro-direct-written interdigitated LIBs. (a) Optical image of LFP ink (60 wt.\% solids) deposited by a $30 \mu \mathrm{m}$ nozzle. (b) SEM micrograph of printed and annealed 16-layer interdigitated LTO-LFP electrode architecture. (c-d) Interdigitated LIBs before and after packaging. (e) Full cell voltage as a function of areal capacity for 8-layer interdigitated LTO-LFP electrodes. (f) Full cell areal capacity of an 8-layer interdigitated LTO-LFP electrode measured as a function of the number of cycles tested. Reproduced with permission. ${ }^{17}$ Copyright 2013 , Wiley$\mathrm{VCH}$.

Solid-state electrolytes are preferred in terms of safety and better mechanical properties. In 2016, Hu et al. reported an allcomponent-printed interdigitated LIB with reasonable battery performance, as shown in Figure $10 .{ }^{44}$ Notably, the authors fabricated this fully-printed LIB using GO-based ink for the electrodes and polymer composite ink for solid-state electrolyte. The polymer ink was prepared by mixing PVDF-co-HFP and $\mathrm{Al}_{2} \mathrm{O}_{3}$ nanoparticles in NMP. This material not only served as a separator, but it also played the role of polymer electrolyte after being soaked in liquid electrolyte. The $\mathrm{Al}_{2} \mathrm{O}_{3} \mathrm{nanoparticles}$ can help improve the ink's wettability and ability to hold the liquid electrolyte in the composite. In the GO-based electrode composite ink, GO serves as a conductive additive as well as an active electrode material after thermal annealing. ${ }^{118}$ Additionally, the highly concentrated aqueous GO dispersions displayed well-controlled shear-thinning and viscoelastic properties, supporting the formation of fine filaments and controlled distances between electrodes. To avoid short circuits, the interdigital distance was intentionally increased, to some extent compromising the power density of printed LIBs. 

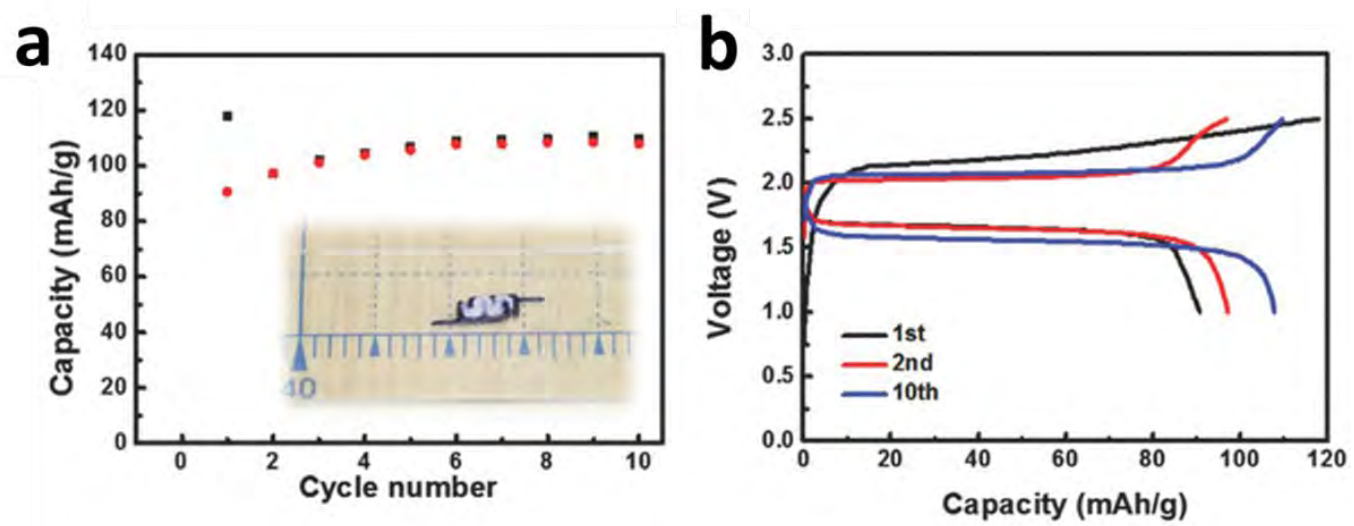

Figure 10. 3D-printed LIBs' architecture and electrochemical performance. (a) Cycling stability of the full 3D-printed cell (LFP as cathode and LTO as anode) at $50 \mathrm{~mA} \mathrm{~g}^{-1}$ (the blue dots represent charge specific capacity, while the red dots represent discharge specific capacity). The LIB maintained $\sim 100 \mathrm{mAh} \mathrm{g}^{-1}$ for ten cycles at a specific current of $50 \mathrm{~mA} \mathrm{~g}^{-1}$. The inset shows the sixlayer electrodes, $7 \mathrm{~mm} \times 3 \mathrm{~mm}$ in size. The polymer electrolyte was injected into the channel between LFP and LTO. (b) The charge/discharge profiles of the $1^{\text {st }}, 2^{\text {nd }} \& 10^{\text {th }}$ cycle at $50 \mathrm{~mA} \mathrm{~g}^{-1}$. The initial charge and discharge capacity were 117 and $91 \mathrm{mAh}$ $\mathrm{g}^{-1}$, respectively, at a current of $50 \mathrm{~mA} \mathrm{~g}^{-1}$. After a few cycles of activation, the charge and discharge capacity reached 110 and $108 \mathrm{mAh} \mathrm{g}^{-1}$, respectively. Reproduced with permission. ${ }^{44}$ Copyright 2016, Wiley-VCH.

Currently, direct ink written LIBs with the conventional sandwich-type architecture tend to have better performance. For example, Wei et al. reported a fully direct ink written sandwich-type LIB $^{119}$ featuring thick biphasic electrodes (as shown in Figure 11a-b) that had a ten-fold enhancement in areal capacity compared to the reference interdigitated LIB. ${ }^{17}$ These investigators prepared four different DIW inks to print the cathode, anode, separator and packaging separately. The biphasic electrode inks were made up of active material particles (LFP or LTO) and Ketjenblack (KB) carbon particles that provided a percolating conductive network. The inks exhibited an ideal viscoelastic response and shear-thinning properties required for DIW. Moreover, the use of UV-curable packaging and separator inks eliminated several steps required in previous DIW LIB assembly processes, including drying, electrolyte filling, and heat sealing. ${ }^{17}$

In conventional LIBs, the electrode materials must be attached to a conducting substrate, namely the current collector. However, metallic foil current collectors, most commonly used, lack stretchability, which limits the form factors of printed LIBs. ${ }^{120}$ This limitation has been overcome with the introduction of carbon nanofibers (CNFs) into the electrode inks. ${ }^{60}$ Here, the conductive CNFs can serve as an embedded current collector, thus eliminating the need for a metallic foil current collector. In addition, CNFs contributed to the formation of a porous electrode structure, facilitating $\mathrm{Li}^{+}$transport and improved high rate performance.

As for printable electrolytes, Blake et al. reported a direct ink written LIB featuring a porous ceramic-polymer electrolyte (Figure 11c-d). ${ }^{61}$ The printable electrolyte ink was formulated with PVDF and $\mathrm{Al}_{2} \mathrm{O}_{3}$ nanoparticles in an NMP/glycerol dual solvent system. Drying-induced phase inversion (PI) generated a uniform and controllable porous structure throughout the ceramic-polymer electrolyte (CPE-PI) matrix. The investigators used sequential printing to deposit this electrolyte ink over an LFP cathode via DIW, forming a printed electrode membrane assembly (PEMA). This sequential printing supported a tight and continuous interface between neighboring layers, thereby retaining the performance of individual layers. The electrochemical performance of this PEMA can reach a capacity of around $160 \mathrm{mAh} \mathrm{g}^{-1}$ at $0.2 \mathrm{C}$ current rates (1 C being defined as $170 \mathrm{~mA} \mathrm{~g}^{-1}$ for LFP).

The above work demonstrates the feasibility of printing LIBs via DIW. However, the electrochemical performance and mechanical properties of DIW LIBs still need further improvement to meet the requirements of advanced wearable electronics. The performance can be improved by printing new active-materials-based battery components or designing special battery architectures from inks with novel formulations. To achieve this, a prerequisite is to have good control of the ink rheology to match the printing process. Moreover, the structures of printed LIBs should be mechanically robust and chemically stable. 


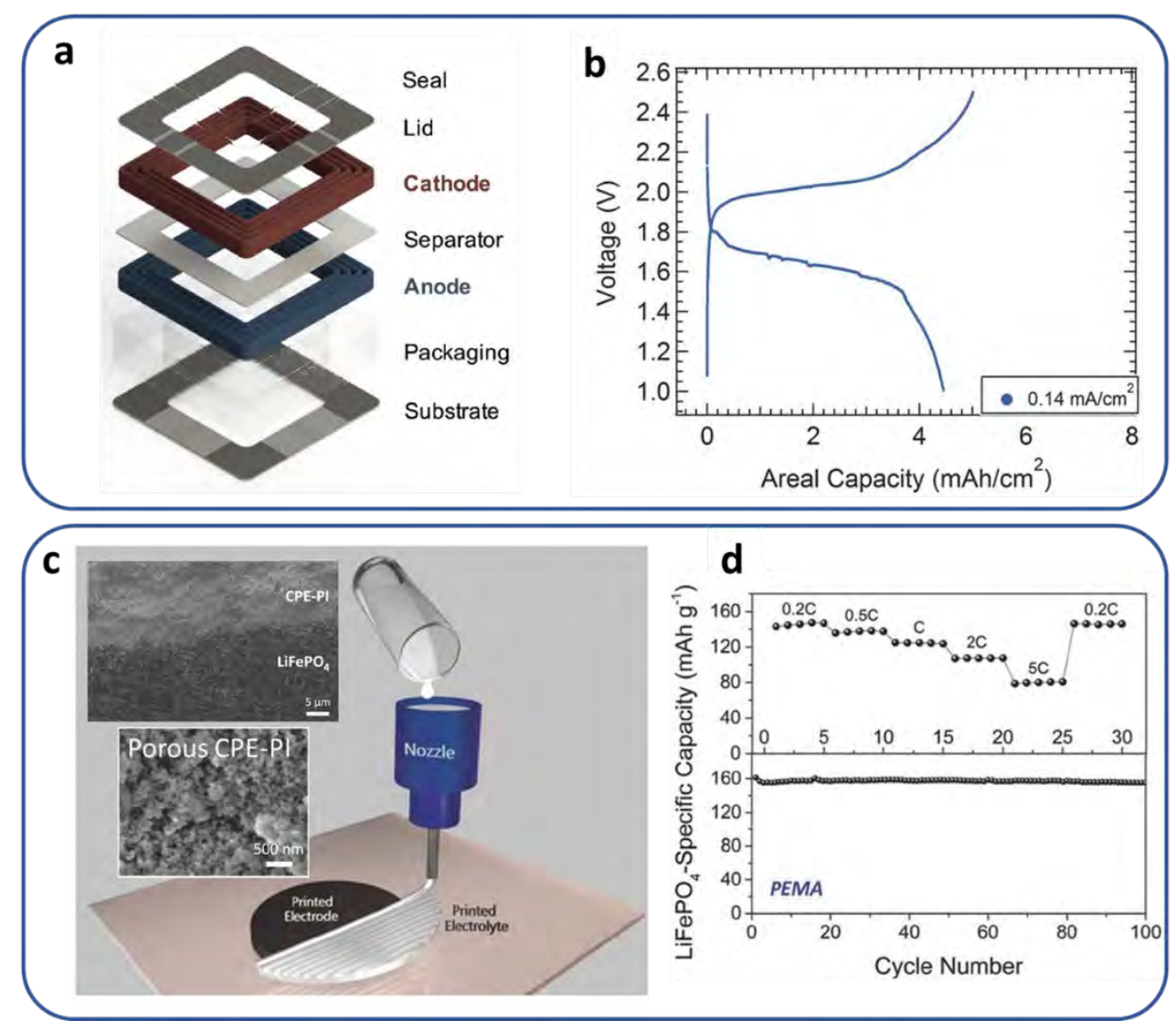

Figure 11. Schematic representations of two direct ink written LIBs and their corresponding electrochemical performance. (a-b) A sandwich-type LIB with thick electrodes can deliver areal capacities of $4.45 \mathrm{mAh} \mathrm{cm}^{-2}$ at $0.14 \mathrm{~mA} \mathrm{~cm}^{-2}$. Reproduced with permission. ${ }^{119}$ Copyright 2018, Wiley-VCH. (c-d) Ceramic-polymer electrolyte ink was printed onto an electrode. The porous structure, as shown in the SEM image, can be obtained via the dry phase inversion method. A smooth and flat interface between electrolyte (CPE-PI) and LFP electrode can also be obtained from this sequential DIW method. Reproduced with permission. ${ }^{61}$ Copyright 2017, Wiley-VCH.

\section{Nanogenerators}

One of the essential challenges for the development of flexible electronics is powering the devices. Apart from direct written batteries (as described above), another promising approach is to incorporate flexible nanogenerators into the overall circuit to support self-powered flexible electronics. ${ }^{121}$ Indeed, flexible nanogenerators have become an emerging research field in the past decade as they can harvest energy from mechanical sources such as human motion, wind energy and wave energy. ${ }^{121,122}$ The most intensely studied nanogenerators are piezoelectric nanogenerators (PENGs), first demonstrated in $2006,{ }^{123}$ and triboelectric nanogenerators (TENGs), first reported in 2012. ${ }^{124}$ In PENGs, the directional migration of free electrons is driven by the electrical potential resulting from the piezoelectric polarization when crystals are deformed under external force. ${ }^{125}$ In contrast, most common TENGs make use of the electric potential formed at the interface region when two different materials contact and separate (vertical contact-separation mode), or slide over each other (lateral sliding mode), driving the flow of electrons. ${ }^{121,126}$

The common active materials for PENGs include zinc oxide (ZnO) and lead zirconate titanate (PZT), ${ }^{121,}{ }^{123}$ but these functional ceramic materials have poor processability and are not suitable for current ink-based 3D printing techniques, thus limiting the development of direct ink written PENGs. In comparison, due to the ubiquity of triboelectrification in nature, a myriad of materials can be applied to TENGs. The key components in a typical TENG, including a scaffold, a polymeric triboelectric layer and a conducting electrode layer, are all printable. Moreover, the fabrication process does not require vacuum or high temperature. ${ }^{127}$ 

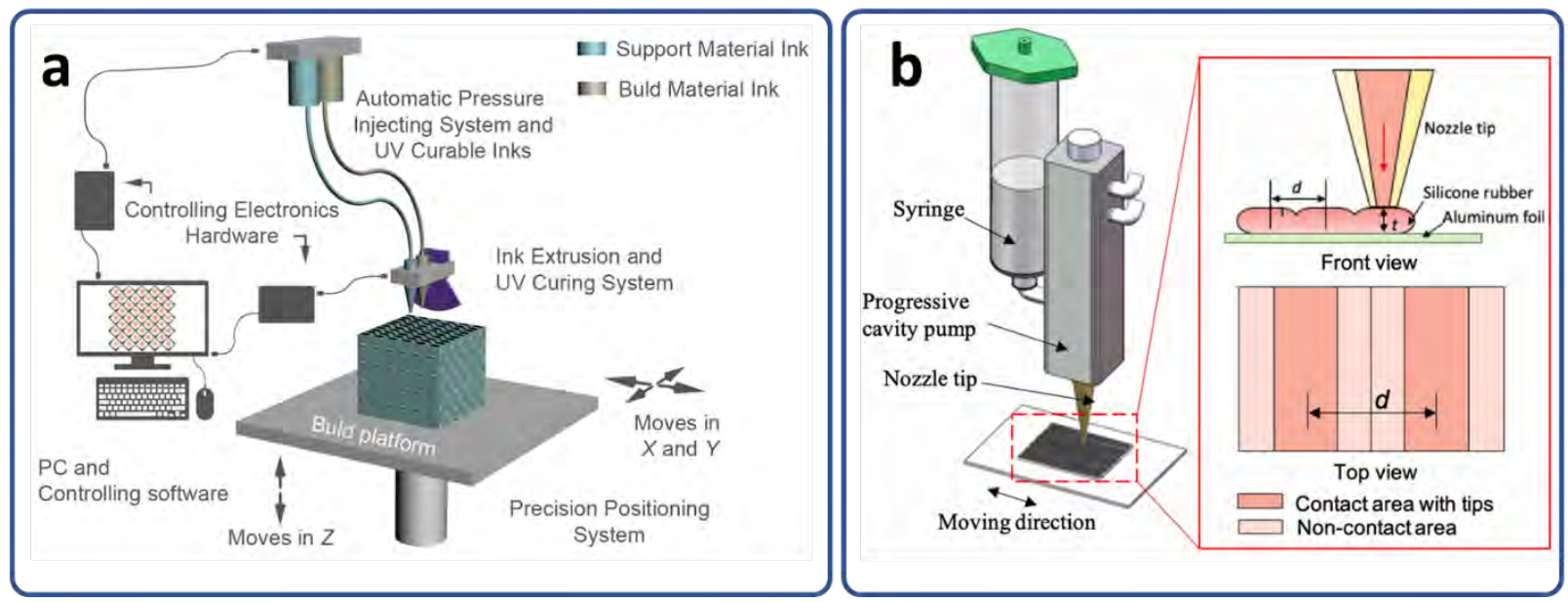

Figure 12. Examples of 3D printed TENGs. (a) Hybrid 3D printing system and 3D ultraflexible TENG. This apparatus consists of an injection, ink extrusion and UV curing system. Composite resin ink and an ionic hydrogel can be printed simultaneously from the two nozzles. Reproduced with permission. ${ }^{30}$ Copyright 2018, Elsevier. (b) Silicone-based TENG DIW fabrication process. The silicone elastomer ink was printed onto a conductive aluminum foil substrate. The cross-sectional shape (regular ridges or dents) varies with the space between each fiber and the distance between the aluminum substrate and nozzle tip. Reproduced with permission. ${ }^{62}$ Copyright 2019, Elsevier.

Recently, Chen et al. fabricated a 3D ultraflexible TENG (Figure 12a) to power wearable devices. ${ }^{30}$ A novelty of this work was the adoption of a new hybrid 3D printing system with double nozzles that injected composite resin and ionic hydrogel to form the triboelectric layer and electrode, respectively. The TENG featured sophisticated high-density feature resolution but maintained ultrahigh flexibility. In 2019, another direct ink written TENG was reported by Li and his coworkers. ${ }^{62}$ They employed fast curing silicone elastomer as an ink to build a double negative triboelectric layer, combined with an aluminum foil (positive triboelectric layer) to form the TENG (Figure 12b). They found that the spacing between the printing fibers and printing paths affected the energy output of the TENG. ${ }^{62}$ Their work shows that DIW has great potential for the fabrication of high performance TENGs. Multiple parameters such as the nozzle size and distance between each fiber were all tunable, thus allowing for the facile optimization of TENG structures. TENGs are usually made from nondegradable and nonrenewable materials. To enhance the sustainability of TENGs, You et al. adopted a poly(glyceril sebacate) (PGS) and CNTs composite as the DIW ink for making an elastic TENG. ${ }^{128}$ The biomaterial PGS is fully biodegradable and, furthermore, the expensive CNTs can be simply recycled and reused after degradation of PGS matrix.

DIW techniques have shown great potential for the design and fabrication of flexible TENGs, although most printed devices still need further optimization of the energy conversion efficiency at this stage. Continued work should develop 3D printed devices with finer feature (micro- and nanoscale printing), more sophisticated geometries and shapes, while also demonstrating scalability, device consistency and cost effectiveness. Miniaturization and new form factors will enable nanogenerators to be integrated into advanced wearable devices.

\section{DIW 3D PRINTERS}

Currently, a variety of DIW 3D printers are available in the market. In general, these printers share a similar working mechanism where DIW ink is forced through a nozzle via a syringe. The control of flow can be achieved by manipulating the pressure on the syringe or opening and closing the nozzle outlet. An example of the latter mechanism is shown in Figure 13 with the nScrypt Smartpump DIW system. In this system, compressed air provides constant back pressure on an inkfilled syringe attached to the nozzle (syringe not shown). A rod with a sealing O-ring (the valve rod) raises and lowers to open and close the nozzle outlet. 


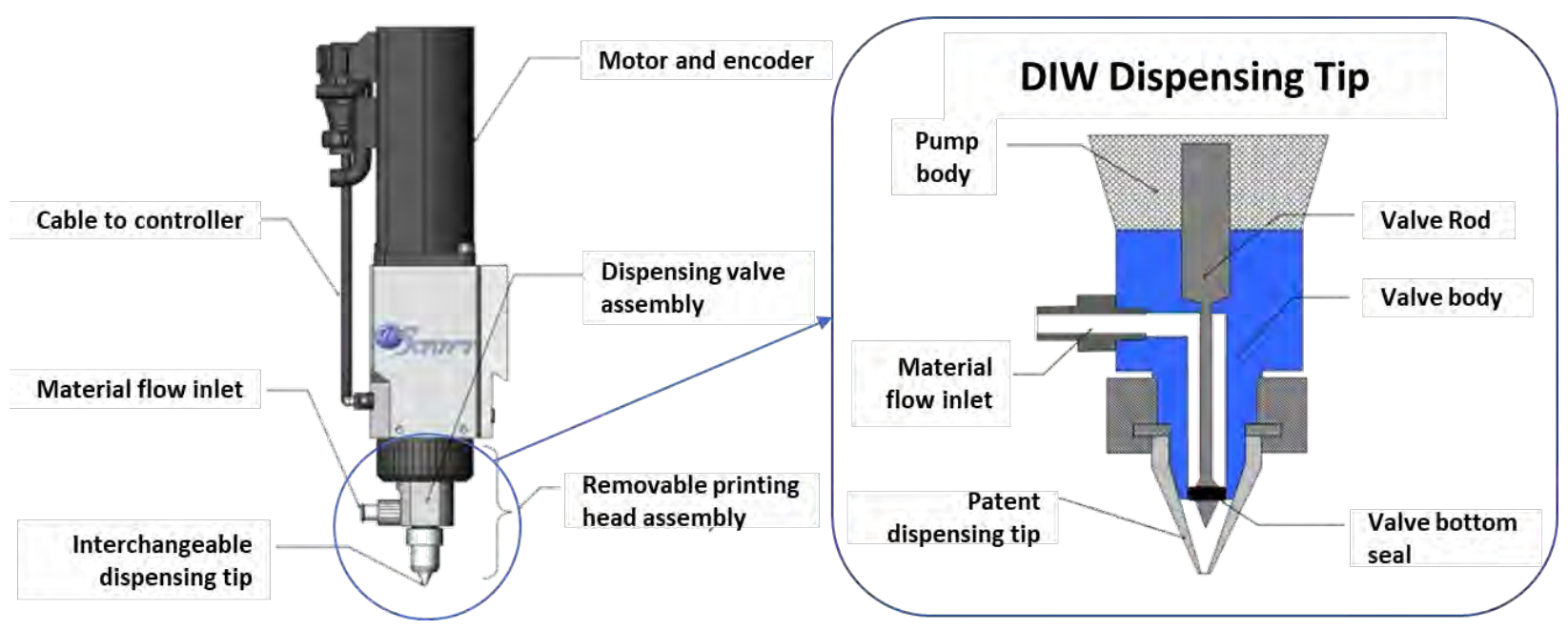

Figure 13. nScrypt Smartpump printing system with cross-sectional view of the dispensing tip. The ink flows into the dispensing tip under pneumatic backpressure. The pump precisely controls the position of the nozzle tip valve seal, allowing for controllable ink flow through the nozzle. Reproduced with permission from nScrypt Inc.

Table 2 lists some DIW 3D printers which have been used to fabricate different devices in the literature. These printers are typically high-end devices with an industrial focus and tend to feature very high resolution. Consumer-level, desktop 3D printers have also been used. ${ }^{129}$ However, these printers lack the resolution required for the intricate circuitry in many of the electronic applications we have described here. 
Table 2. Commercially available DIW 3D printers and their specifications.

\begin{tabular}{|c|c|c|}
\hline Printer (Company) & Applications & Printer Specifications and Parameters Used \\
\hline $\begin{array}{l}\text { Fisnar F4200n Benchtop Robot } \\
\text { (Fisnar Inc.) }\end{array}$ & $\begin{array}{l}\text { GO electrodes } \\
\text { LIBs }^{44}\end{array}$ & $\begin{array}{l}\text { Air-powered fluid dispenser (DSP501N, Fisnar) } \\
\text { Tip diameter: } 203.2 \mu \mathrm{m}\end{array}$ \\
\hline $\begin{array}{l}\text { NoveGen MMX Bioprinter } \\
\text { (Organovo Inc.) }\end{array}$ & Biological applications ${ }^{19}$ & $\begin{array}{l}\text { Capillary-piston (Diameter: } 500 \mu \mathrm{m}) \\
\text { Ejection rate: } 23.6 \mu 1 / \mathrm{min}\end{array}$ \\
\hline 3Dn-300 printer (nScript Inc.) & $\begin{array}{l}\text { Solid-state batteries }{ }^{130} \text {, } \\
131\end{array}$ & $\begin{array}{l}\text { Pressure-driven syringe with adjustable nozzle valve opening } \\
\text { Ceramic nozzles }(12.5-125 \mu \mathrm{m}) \\
\text { Gas extrusion pressure: } 0-100 \mathrm{psi}\end{array}$ \\
\hline \multirow{2}{*}{$\begin{array}{l}\text { Aerotech 3D-motion gantry } \\
\text { (Pittsburgh, PA) and Ultimus V } \\
\text { pressure pump system (Nordson } \\
\text { EFD, East Providence, RI) }\end{array}$} & $\begin{array}{l}\text { AgTPU soft } \\
\text { electronics }^{29}\end{array}$ & $\begin{array}{l}\text { Tip diameter: } 410 \mu \mathrm{m} \text { (for the insulating TPU matrix) } \\
\text { Tip diameter: } 200 \mu \mathrm{m} \text { (for the conductive AgTPU inks) }\end{array}$ \\
\hline & $\mathrm{LIBs}^{60,61}$ & $\begin{array}{l}\text { Motion speed } 5-20 \mathrm{~mm} \mathrm{~s}^{-1} \\
\text { Pressure } 0.5-5 \text { psi for electrode inks } \\
\text { Pressure } 5-25 \text { psi for electrolyte inks } \\
\text { Stainless steel syringe tips (Nordson EFD, } 18-25 \text { gauge and } 1 / 4- \\
1 / 2 \text { in. in length) }\end{array}$ \\
\hline $\begin{array}{l}\text { Bioprinter (Hangzhou Shining } \\
\text { 3D Tech Co., Ltd. \& Hangzhou } \\
\text { Regenovo Biotechnology Co., } \\
\text { Ltd.) }\end{array}$ & $\begin{array}{l}\text { Graphene-based mixed- } \\
\text { dimensional hybrid } \\
\text { aerogels for energy } \\
\text { storage applications }^{46}\end{array}$ & $\begin{array}{l}60 \mu \mathrm{m} \text { nozzle } \\
\text { Printing speed } \sim 4 \mathrm{~mm} \mathrm{~s}^{-1} \text { under } 1 \text { bar (14.5 psi) }\end{array}$ \\
\hline $\begin{array}{l}\text { Anet A8 (Shenzhen Anet } \\
\text { Technology Co., China) and } \\
\text { Ultimus V pressure pump } \\
\text { system (Nordson EFD, USA) }\end{array}$ & $\begin{array}{l}\text { Liquid metal stretchable } \\
\text { electronics }{ }^{42}\end{array}$ & $\begin{array}{l}\text { Stainless steel needles with an inner diameter of } 0.84 \mathrm{~mm} \\
\text { Printing speed } 30 \sim 50 \mathrm{~mm} \mathrm{~s}^{-1} \text { under the pressure of } 20 \mathrm{psi} \text {. }\end{array}$ \\
\hline
\end{tabular}

\section{CONCLUSIONS AND PERSPECTIVES}

Compared to conventional fabrication methods, DIW techniques have unique advantages, including precisely controlled deposition of materials into unique 3D structures. Recent work has demonstrated sophisticated architectures using nanomaterials-based inks with tunable rheological properties. To precisely manipulate the DIW process, the relationship among DIW printer systems, ink formulations and functionalities of printed products is important. By using specific ink formulations, DIW can effectively and reproducibly create various wearable electronics. Customizable DIW techniques can optimize internal functional structures to meet the demands of wearable devices. In particular, due to the controllable deposition in the z-direction, high resolution DIW techniques are advantageous in printing many conformal wearable devices with small thickness, on the scale of few micrometers. To this end, 3D DIW has been successfully deployed for several types of tactile/strain sensors. Further, several important proofs of concept have been shown for DIW LIBs and nanogenerators, but future work is needed to integrate these components into wearables.

A number of other fundamental challenges still need to be addressed and improved for DIW electronics. The rheological properties of inks play an essential role in determining the printed structure of resulting devices, but a clear link between the rheological properties of inks and the device performance should be elucidated. For DIW, high viscosity ink is generally required such that the ink prefers to retain its shape after deposition, but this increases the complexity of the ink components 
and the chances of nozzle clogging. Research might further explore the use of simple low viscosity ink with other in situ curing processes, in addition to photo- or thermal- curing. The in situ curing process should ideally add functionalities or improve device performance in addition to supporting the 3D printed structures.

The performance of many 3D printed electronics is still inferior to state-of-art conventional devices (this is the case for the energy densities and power densities of printed lithium batteries and the energy output of flexible piezoelectric nanogenerators). Therefore, further optimization of ink formulas or printing strategies must be explored to capitalize on the unique advantages of DIW (e.g. shear-induced nano-structuring) for improving device performance. With the rapid advancement in robotics and automation, there is no doubt that DIW technology can be integrated into existing production lines: from the construction of interconnects to the fabrication of critical functional components. A pragmatic limitation of many of the reported devices is the cost of material inputs. Hence, to reach eventual commercialization, the production scalability and cost-effectiveness of nanomaterials must be improved.

Despite some existing challenges, research and development on direct ink written wearable electronics is still in an early stage. Researchers thus far have developed an impressive array of strategies to overcome the challenges inherent in DIW. With concurrent innovations in material science and 3D printing technology, higher performance wearable electronic devices with better stability and functionalities will almost certainly be designed and demonstrated.

\section{AUTHOR INFORMATION}

\section{Corresponding Authors}

*E-mail: y.zhong@griffith.edu.au

\section{Author Contributions}

$\ddagger$ Y. Zhang and S. Ge contributed equally to this work.

\section{Notes}

The authors declare no competing financial interest.

\section{ACKNOWLEDGMENT}

The authors acknowledge the support from the Australian Research Council (DP190100120 and LP160101521). 


\section{REFERENCES}

1. Yeo, J. C.; Lim, C. T., Emerging flexible and wearable physical sensing platforms for healthcare and biomedical applications. Microsyst. Nanoeng. 2016, 2, 16043.

2. $\quad$ Chang, J.-K.; Chang, H.-P.; Guo, Q.; Koo, J.; Wu, C.-I.; Rogers, J. A., Biodegradable Electronic Systems in 3D, Heterogeneously Integrated Formats. Adv. Mater. 2018, 30 (11), 1704955.

3. Guo, S. Z.; Qiu, K.; Meng, F.; Park, S. H.; McAlpine, M. C., 3D printed stretchable tactile sensors. Adv. Mater. 2017, 29 (27), 1701218.

4. $\quad$ Wang, S.; Gong, L.; Shang, Z.; Ding, L.; Yin, G.; Jiang, W.; Gong, X.; Xuan, S., Novel Safeguarding Tactile e-Skins for Monitoring Human Motion Based on SST/PDMS-AgNW-PET Hybrid Structures. Adv. Funct. Mater. 2018,28 (18), 1707538.

5. Khan, U.; Kim, T. H.; Ryu, H.; Seung, W.; Kim, S. W., Graphene tribotronics for electronic skin and touch screen applications. Adv. Mater. 2017, 29 (1), 1603544.

6. $\quad$ Shin, E. Y.; Cho, H. J.; Jung, S.; Yang, C.; Noh, Y. Y., A High-k Fluorinated P (VDF-TrFE)-g-PMMA Gate Dielectric for High-Performance Flexible Field-Effect Transistors. Adv. Funct. Mater. 2018, 28 (4), 1704780.

7. $\quad$ Li, W.; Li, F.; Li, H.; Su, M.; Gao, M.; Li, Y.; Su, D.; Zhang, X.; Song, Y., Flexible Circuits and Soft Actuators by Printing Assembly of Graphene. ACS Appl. Mater. Interfaces 2016, 8 (19), 12369-12376.

8. Gao, M.; Li, L.; Li, W.; Zhou, H.; Song, Y., Direct Writing of Patterned, Lead-Free Nanowire Aligned Flexible Piezoelectric Device. Advanced science 2016, 3 (8), 1600120-1600120.

9. $\quad$ Wang, Y.; Chen, C.; Xie, H.; Gao, T.; Yao, Y.; Pastel, G.; Han, X.; Li, Y.; Zhao, J.; Fu, K. K., 3D-Printed All-Fiber Li-Ion Battery toward Wearable Energy Storage. Adv. Funct. Mater. 2017, 27 (43), 1703140.

10. Takei, K.; Honda, W.; Harada, S.; Arie, T.; Akita, S., Toward Flexible and Wearable Human-Interactive HealthMonitoring Devices. Adv. Healthcare Mater. 2015, 4 (4), 487-500.

11. Zhang, Z.; Liao, M.; Lou, H.; Hu, Y.; Sun, X.; Peng, H., Conjugated Polymers for Flexible Energy Harvesting and Storage. Adv. Mater. 2018, 1704261.

12. Kim, J.; Kumar, R.; Bandodkar, A. J.; Wang, J., Advanced materials for printed wearable electrochemical devices: A review. Adv. Electron. Mater. 2017, 3 (1), 1600260.

13. Lewis, J. A., Direct Ink Writing of 3D Functional Materials. Adv. Funct. Mater. 2006, 16 (17), $2193-2204$.

14. Lao, Z.; Hu, Y.; Zhang, C.; Yang, L.; Li, J.; Chu, J.; Wu, D., Capillary force driven self-assembly of anisotropic hierarchical structures prepared by femtosecond laser 3D printing and their applications in crystallizing microparticles. ACS Nano 2015, 9 (12), 12060-12069.

15. $\quad$ Lewis, J. A.; Gratson, G. M., Direct writing in three dimensions. Mater. Today 2004, 7 (7-8), 32-39.

16. Yuk, H.; Zhao, X., A New 3D Printing Strategy by Harnessing Deformation, Instability, and Fracture of Viscoelastic Inks. Adv. Mater. 2018, 30 (6), 1704028.

17. Sun, K.; Wei, T.-S.; Ahn, B. Y.; Seo, J. Y.; Dillon, S. J.; Lewis, J. A., 3D Printing of Interdigitated Li-Ion Microbattery Architectures. Adv. Mater. 2013, 25 (33), 4539-4543.

18. Kong, Y. L.; Tamargo, I. A.; Kim, H.; Johnson, B. N.; Gupta, M. K.; Koh, T.-W.; Chin, H.-A.; Steingart, D. A.; Rand, B. P.; McAlpine, M. C., 3D Printed Quantum Dot Light-Emitting Diodes. Nano Lett. 2014, 14 (12), 7017-7023.

19. Shin, S. R.; Farzad, R.; Tamayol, A.; Manoharan, V.; Mostafalu, P.; Zhang, Y. S.; Akbari, M.; Jung, S. M.; Kim, D.; Comotto, M., A Bioactive Carbon Nanotube-Based Ink for Printing 2D and 3D Flexible Electronics. Adv. Mater. 2016, 28 (17), 3280-3289.

20. Li, R.-Z.; Hu, A.; Zhang, T.; Oakes, K. D., Direct Writing on Paper of Foldable Capacitive Touch Pads with Silver Nanowire Inks. ACS Appl. Mater. Interfaces 2014, 6 (23), 21721-21729.

21. Secor, E. B.; Ahn, B. Y.; Gao, T. Z.; Lewis, J. A.; Hersam, M. C., Rapid and Versatile Photonic Annealing of Graphene Inks for Flexible Printed Electronics. Adv. Mater. 2015, 27 (42), 6683-6688.

22. $\quad$ Ma, Y.; Liu, N.; Li, L.; Hu, X.; Zou, Z.; Wang, J.; Luo, S.; Gao, Y., A highly flexible and sensitive piezoresistive sensor based on MXene with greatly changed interlayer distances. Nat. Commun. 2017, 8 (1), 1207.

23. Hu, J.; Jiang, Y.; Cui, S.; Duan, Y.; Liu, T.; Guo, H.; Lin, L.; Lin, Y.; Zheng, J.; Amine, K.; Pan, F., 3D-Printed Cathodes of LiMn1-xFexPO4 Nanocrystals Achieve Both Ultrahigh Rate and High Capacity for Advanced Lithium-Ion Battery. Adv. Energy Mater. 2016, 6 (18), 1600856.

24. $\quad$ Lacey, S. D.; Kirsch, D. J.; Li, Y.; Morgenstern, J. T.; Zarket, B. C.; Yao, Y.; Dai, J.; Garcia, L. Q.; Liu, B.; Gao, T., Extrusion-Based 3D Printing of Hierarchically Porous Advanced Battery Electrodes. Adv. Mater. 2018, 30 (12), 1705651.

25. Jakus, A. E.; Secor, E. B.; Rutz, A. L.; Jordan, S. W.; Hersam, M. C.; Shah, R. N., Three-Dimensional Printing of High-Content Graphene Scaffolds for Electronic and Biomedical Applications. ACS Nano 2015, 9 (4), 4636-4648.

26. Dickey, M. D., Stretchable and Soft Electronics using Liquid Metals. Adv. Mater. 2017, 29 (27), 1606425.

27. Yang, Y.; Sun, N.; Wen, Z.; Cheng, P.; Zheng, H.; Shao, H.; Xia, Y.; Chen, C.; Lan, H.; Xie, X., Liquid-metalbased super-stretchable and structure-designable triboelectric nanogenerator for wearable electronics. ACS Nano 2018, 12 (2), 2027-2034.

28. Gratson, G. M.; Xu, M.; Lewis, J. A., Direct writing of three-dimensional webs. Nature 2004, 428, 386.

29. Valentine, A. D.; Busbee, T. A.; Boley, J. W.; Raney, J. R.; Chortos, A.; Kotikian, A.; Berrigan, J. D.; Durstock, M. F.; Lewis, J. A., Hybrid 3D printing of soft electronics. Adv. Mater. 2017, 29 (40), 1703817. 
30. Chen, B. D.; Tang, W.; Jiang, T.; Zhu, L. P.; Chen, X. Y.; He, C.; Xu, L.; Guo, H. Y.; Lin, P.; Li, D.; Shao, J. J.; Wang, Z. L., Three-dimensional ultraflexible triboelectric nanogenerator made by 3D printing. Nano Energy 2018, 45, 380-389.

31. Gratson, G. M.; García-Santamaría, F.; Lousse, V.; Xu, M.; Fan, S.; Lewis, J. A.; Braun, P. V., Direct-write assembly of three-dimensional photonic crystals: conversion of polymer scaffolds to silicon hollow-woodpile structures. Adv. Mater. 2006, 18 (4), 461-465.

32. Li, Q.; Lewis, J. A., Nanoparticle Inks for Directed Assembly of Three-Dimensional Periodic Structures. Adv. Mater. 2003, 15 (19), 1639-1643.

33. Li, Y.-y.; Li, L.-t.; Li, B., Direct write printing of three-dimensional ZrO2 biological scaffolds. Mater. Des. 2015, 72, 16-20.

34. Kolesky, D. B.; Truby, R. L.; Gladman, A. S.; Busbee, T. A.; Homan, K. A.; Lewis, J. A., 3D Bioprinting of Vascularized, Heterogeneous Cell-Laden Tissue Constructs. Adv. Mater. 2014, 26 (19), 3124-3130.

35. Hardin, J. O.; Ober, T. J.; Valentine, A. D.; Lewis, J. A., Microfluidic Printheads for Multimaterial 3D Printing of Viscoelastic Inks. Adv. Mater. 2015, 27 (21), 3279-3284.

36. Z Zhu, P.; Yang, W.; Wang, R.; Gao, S.; Li, B.; Li, Q., Direct Writing of Flexible Barium Titanate/Polydimethylsiloxane 3D Photonic Crystals with Mechanically Tunable Terahertz Properties. Adv. Opt. Mater 2017, 5 (7), 1600977.

37. Park, Y.-G.; Min, H.; Kim, H.; Zhexembekova, A.; Lee, C. Y.; Park, J.-U., Three-Dimensional, High-Resolution Printing of Carbon Nanotube/Liquid Metal Composites with Mechanical and Electrical Reinforcement. Nano Lett. 2019, https://doi.org/10.1021/acs.nanolett.9b00150.

38. $\quad$ Muth, J. T.; Vogt, D. M.; Truby, R. L.; Mengüç, Y.; Kolesky, D. B.; Wood, R. J.; Lewis, J. A., Embedded 3D Printing of Strain Sensors within Highly Stretchable Elastomers. Adv. Mater. 2014, 26 (36), 6307-6312.

39. Herschel, W. H.; Bulkley, R., Konsistenzmessungen von Gummi-Benzollösungen. Kolloid-Zeitschrift 1926, 39 (4), 291-

300.

40. M’Barki, A.; Bocquet, L.; Stevenson, A., Linking Rheology and Printability for Dense and Strong Ceramics by Direct Ink Writing. Sci. Rep. 2017, 7 (1), 6017.

41. Friedrich, L.; Begley, M., In situ characterization of low-viscosity direct ink writing: Stability, wetting, and rotational flows. J. Colloid Interface Sci. 2018, 529, 599-609.

42. Daalkhaijav, U.; Yirmibesoglu, O. D.; Walker, S.; Mengüç, Y., Rheological Modification of Liquid Metal for Additive Manufacturing of Stretchable Electronics. Adv. Mater. Technol. 2018, 3 (4), 1700351.

43. Chen, W.; Thornley, L.; Coe, H. G.; Tonneslan, S. J.; Vericella, J. J.; Zhu, C.; Duoss, E. B.; Hunt, R. M.; Wight, M. J.; Apelian, D.; Pascall, A. J.; Kuntz, J. D.; Spadaccini, C. M., Direct metal writing: Controlling the rheology through microstructure. Appl. Phys. Lett. 2017, 110 (9), 094104.

44. $\quad$ Fu, K.; Wang, Y.; Yan, C.; Yao, Y.; Chen, Y.; Dai, J.; Lacey, S.; Wang, Y.; Wan, J.; Li, T.; Wang, Z.; Xu, Y.; Hu, L., Graphene Oxide-Based Electrode Inks for 3D-Printed Lithium-Ion Batteries. Adv. Mater. 2016, 28 (13), $2587-2594$.

45. Compton, B. G.; Lewis, J. A., 3D-Printing of Lightweight Cellular Composites. Adv. Mater. 2014, 26 (34), $5930-5935$.

46. Tang, X.; Zhou, H.; Cai, Z.; Cheng, D.; He, P.; Xie, P.; Zhang, D.; Fan, T., Generalized 3D Printing of GrapheneBased Mixed-Dimensional Hybrid Aerogels. ACS Nano 2018, 12 (4), 3502-3511.

47. Ahn, B. Y.; Duoss, E. B.; Motala, M. J.; Guo, X.; Park, S.-I.; Xiong, Y.; Yoon, J.; Nuzzo, R. G.; Rogers, J. A.; Lewis, J. A., Omnidirectional Printing of Flexible, Stretchable, and Spanning Silver Microelectrodes. Science 2009, 323 (5921), 1590-1593.

48. Li, W.; Li, Y.; Su, M.; An, B.; Liu, J.; Su, D.; Li, L.; Li, F.; Song, Y., Printing assembly and structural regulation of graphene towards three-dimensional flexible micro-supercapacitors. J. Mater. Chem. A 2017, 5 (31), 16281-16288.

49. $\quad$ Azhari, A.; Marzbanrad, E.; Yilman, D.; Toyserkani, E.; Pope, M. A., Binder-jet powder-bed additive manufacturing (3D printing) of thick graphene-based electrodes. Carbon 2017, 119, 257-266.

50. Luque-Garcia, J.; De Castro, M. L., Ultrasound: a powerful tool for leaching. Trends Anal. Chem. 2003, 22 (1), $41-47$.

51. Huang, Y.; Zeng, L.; Liu, C.; Zeng, D.; Liu, Z.; Liu, X.; Zhong, X.; Guo, W.; Li, L., Laser Direct Writing of Heteroatom (N and S)-Doped Graphene from a Polybenzimidazole Ink Donor on Polyethylene Terephthalate Polymer and Glass Substrates. Small 2018, 14 (44), 1803143.

52. Wu, X.; Xu, Y.; Hu, Y.; Wu, G.; Cheng, H.; Yu, Q.; Zhang, K.; Chen, W.; Chen, S., Microfluidic-spinning construction of black-phosphorus-hybrid microfibres for non-woven fabrics toward a high energy density flexible supercapacitor. Nat. Commun. 2018, 9 (1), 4573.

53. Zang, X.; Hohman, J. N.; Yao, K.; Ci, P.; Yan, A.; Wei, M.; Hayasaka, T.; Zettl, A.; Schuck, P. J.; Wu, J.; Lin, L., Metallo-Hydrogel-Assisted Synthesis and Direct Writing of Transition Metal Dichalcogenides. Adv. Funct. Mater. $2019,1807612$. 54. Zhang, C.; McKeon, L.; Kremer, M. P.; Park, S.-H.; Ronan, O.; Seral-Ascaso, A.; Barwich, S.; Coileáin, C. Ó.; McEvoy, N.; Nerl, H. C.; Anasori, B.; Coleman, J. N.; Gogotsi, Y.; Nicolosi, V., Additive-free MXene inks and direct printing of micro-supercapacitors. Nat. Commun. 2019, 10 (1), 1795.

55. Jason, N. N.; Shen, W.; Cheng, W., Copper Nanowires as Conductive Ink for Low-Cost Draw-On Electronics. ACS Appl. Mater. Interfaces 2015, 7 (30), 16760-16766.

56. Wei, P.; Leng, H.; Chen, Q.; Advincula, R. C.; Pentzer, E. B., Reprocessable 3D-Printed Conductive Elastomeric Composite Foams for Strain and Gas Sensing. ACS Appl. Polym. Mater. 2019, 1 (4), 885-892.

57. Wang, Z.; Guan, X.; Huang, H.; Wang, H.; Lin, W.; Peng, Z., Full 3D Printing of Stretchable Piezoresistive Sensor with Hierarchical Porosity and Multimodulus Architecture. Adv. Funct. Mater. 2019, 29 (11), 1807569. 
58. Kim, S.; Oh, J.; Jeong, D.; Bae, J., Direct Wiring of Eutectic Gallium-Indium to a Metal Electrode for Soft Sensor Systems. ACS Appl. Mater. Interfaces 2019, 11 (22), 20557-20565.

59. Li, J.; Leu, M. C.; Panat, R.; Park, J., A hybrid three-dimensionally structured electrode for lithium-ion batteries via 3D printing. Mater. Des. 2017, 119, 417-424.

60. Kohlmeyer, R. R.; Blake, A. J.; Hardin, J. O.; Carmona, E. A.; Carpena-Núñez, J.; Maruyama, B.; Daniel Berrigan, J.; Huang, H.; Durstock, M. F., Composite batteries: a simple yet universal approach to 3D printable lithium-ion battery electrodes. J. Mater. Chem. A 2016, 4 (43), 16856-16864.

61. Blake, A. J.; Kohlmeyer, R. R.; Hardin, J. O.; Carmona, E. A.; Maruyama, B.; Berrigan, J. D.; Huang, H.; Durstock, M. F., 3D Printable Ceramic-Polymer Electrolytes for Flexible High-Performance Li-Ion Batteries with Enhanced Thermal Stability. Adv. Energy Mater. 2017, 7 (14), 1602920.

62. Li, H.; Li, R.; Fang, X.; Jiang, H.; Ding, X.; Tang, B.; Zhou, G.; Zhou, R.; Tang, Y., 3D printed flexible triboelectric nanogenerator with viscoelastic inks for mechanical energy harvesting. Nano Energy 2019, 58, 447-454.

63. Thongrattanasiri, S.; Koppens, F. H.; de Abajo, F. J. G., Complete optical absorption in periodically patterned graphene. Phys. Rev. Lett. 2012, 108 (4), 047401.

64. Bolotin, K. I.; Sikes, K.; Jiang, Z.; Klima, M.; Fudenberg, G.; Hone, J.; Kim, P.; Stormer, H., Ultrahigh electron mobility in suspended graphene. Solid State Commun. 2008, 146 (9), 351-355.

65. Stankovich, S.; Dikin, D. A.; Dommett, G. H.; Kohlhaas, K. M.; Zimney, E. J.; Stach, E. A.; Piner, R. D.; Nguyen, S. T.; Ruoff, R. S., Graphene-based composite materials. Nature 2006, 442 (7100), 282-286.

66. Lee, C.; Wei, X.; Kysar, J. W.; Hone, J., Measurement of the elastic properties and intrinsic strength of monolayer graphene. Science 2008, 321 (5887), 385-388.

67. Lowe, S. E.; Zhong, Y., Challenges of industrial-scale graphene oxide production. In Graphene Oxide. Fundamentals and Applications, Dimiev, A. M.; Eigler, S., Eds. John Wiley \& Sons: Oxford, 2015.

68. Lowe, S. E.; Shi, G.; Zhang, Y.; Qin, J.; Wang, S.; Uijtendaal, A.; Sun, J.; Jiang, L.; Jiang, S.; Qi, D.; Al-Mamun, M.; Liu, P.; Zhong, Y. L.; Zhao, H., Scalable Production of Graphene Oxide Using a 3D-Printed Packed-Bed Electrochemical Reactor with a Boron-Doped Diamond Electrode. ACS Appl. Nano Mater. 2019, 867-878.

69. Yu, P.; Lowe, S. E.; Simon, G. P.; Zhong, Y. L., Electrochemical exfoliation of graphite and production of functional graphene. Curr. Opin. Colloid Interface Sci. 2015, 20 (5-6), 329-338.

70. Yu, P.; Tian, Z.; Lowe, S. E.; Song, J.; Ma, Z.; Wang, X.; Han, Z. J.; Bao, Q.; Simon, G. P.; Li, D.; Zhong, Y., Mechanically-Assisted Electrochemical Production of Graphene Oxide. Chem. Mater. 2016, 28 (22), 8429-8438.

71. Qin, J.; Zhang, Y.; Lowe, S. E.; Jiang, L.; Ling, H. Y.; Shi, G.; Liu, P.; Zhang, S.; Zhong, Y. L.; Zhao, H., Room temperature production of graphene oxide with thermally labile oxygen functional groups for improved lithium ion battery fabrication and performance. J. Mater. Chem. A 2019, 7 (16), 9646-9655.

72. $\quad$ Zhong, Y. L.; Tian, Z.; Simon, G. P.; Li, D., Scalable production of graphene via wet chemistry: progress and challenges. Mater. Today 2015, 18 (2), 73-78.

73. Jakus, A. E.; Shah, R. N., Multi and mixed 3 D-printing of graphene-hydroxyapatite hybrid materials for complex tissue engineering. J. Biomed. Mater. Res. Part A 2017, 105 (1), 274-283.

74. You, X.; Yang, J.; Feng, Q.; Huang, K.; Zhou, H.; Hu, J.; Dong, S., Three-dimensional graphene-based materials by direct ink writing method for lightweight application. International Journal of Lightweight Materials and Manufacture 2018, 1 (2), 96-101.

75. Z Zhang, Q.; Zhang, F.; Medarametla, S. P.; Li, H.; Zhou, C.; Lin, D., 3D printing of graphene aerogels. Small 2016, 12 (13), 1702-1708.

76. $\quad$ Naficy, S.; Jalili, R.; Aboutalebi, S. H.; Gorkin III, R. A.; Konstantinov, K.; Innis, P. C.; Spinks, G. M.; Poulin, P.; Wallace, G. G., Graphene oxide dispersions: tuning rheology to enable fabrication. Mater. Horiz. 2014, 1 (3), 326-331.

77. Schnurr, B.; Gittes, F.; MacKintosh, F.; Schmidt, C., Determining microscopic viscoelasticity in flexible and semiflexible polymer networks from thermal fluctuations. Macromolecules 1997, 30 (25), 7781-7792.

78. Zrnic, D.; Swatik, D. S., On the resistivity and surface tension of the eutectic alloy of gallium and indium. J. LessCommon Met. 1969, 18 (1), 67-68.

79. Spells, K. E., The determination of the viscosity of liquid gallium over an extended nrange of temperature. Proc. Phys. Soc 1936, 48 (2), 299-311.

80. Dickey, M. D., Emerging Applications of Liquid Metals Featuring Surface Oxides. ACS Appl. Mater. Interfaces 2014, 6 (21), 18369-18379.

81. $\quad$ Chossat, J.; Park, Y.; Wood, R. J.; Duchaine, V., A Soft Strain Sensor Based on Ionic and Metal Liquids. IEEE Sensors Journal 2013, 13 (9), 3405-3414.

82. Dickey, M. D.; Chiechi, R. C.; Larsen, R. J.; Weiss, E. A.; Weitz, D. A.; Whitesides, G. M., Eutectic Gallium-Indium (EGaIn): A Liquid Metal Alloy for the Formation of Stable Structures in Microchannels at Room Temperature. Adv. Funct. Mater. 2008, 18 (7), 1097-1104.

83. Ladd, C.; So, J.-H.; Muth, J.; Dickey, M. D., 3D Printing of Free Standing Liquid Metal Microstructures. Adv. Mater. 2013, 25 (36), 5081-5085.

84. Wang, Q.; Yu, Y.; Yang, J.; Liu, J., Fast Fabrication of Flexible Functional Circuits Based on Liquid Metal Dual-Trans Printing. Adv. Mater. 2015, 27 (44), 7109-7116. 
85. Boley, J. W.; White, E. L.; Chiu, G. T. C.; Kramer, R. K., Direct Writing of Gallium-Indium Alloy for Stretchable Electronics. Adv. Funct. Mater. 2014, 24 (23), 3501-3507.

86. Truby, R. L.; Lewis, J. A., Printing soft matter in three dimensions. Nature 2016, 540, 371.

87. Mohammed, M. G.; Kramer, R., All-Printed Flexible and Stretchable Electronics. Adv. Mater. 2017, 29 (19), 1604965.

88. Mu, Q.; Dunn, C. K.; Wang, L.; Dunn, M. L.; Qi, H. J.; Wang, T., Thermal cure effects on electromechanical properties of conductive wires by direct ink write for 4D printing and soft machines. Smart Mater. Struct. 2017, 26 (4), 045008.

89. $\quad$ Chen, B.; Jiang, Y.; Tang, X.; Pan, Y.; Hu, S., Fully Packaged Carbon Nanotube Supercapacitors by Direct Ink Writing on Flexible Substrates. ACS Appl. Mater. Interfaces 2017, 9 (34), 28433-28440.

90. Patel, S.; Park, H.; Bonato, P.; Chan, L.; Rodgers, M., A review of wearable sensors and systems with application in rehabilitation. J. NeuroEng. Rehabil. 2012, 9 (1), 21.

91. Roh, E.; Hwang, B.-U.; Kim, D.; Kim, B.-Y.; Lee, N.-E., Stretchable, Transparent, Ultrasensitive, and Patchable Strain Sensor for Human-Machine Interfaces Comprising a Nanohybrid of Carbon Nanotubes and Conductive Elastomers. ACS Nano 2015, 9 (6), 6252-6261.

92. $\quad$ Schwartz, G.; Tee, B. C. K.; Mei, J.; Appleton, A. L.; Kim, D. H.; Wang, H.; Bao, Z., Flexible polymer transistors with high pressure sensitivity for application in electronic skin and health monitoring. Nat. Commun. 2013, 4, 1859.

93. Gong, S.; Cheng, W., Toward Soft Skin-Like Wearable and Implantable Energy Devices. Adv. Energy Mater. 2017, 7 (23), 1700648.

94. $\quad$ Gong, S.; Lai, D. T.; Su, B.; Si, K. J.; Ma, Z.; Yap, L. W.; Guo, P.; Cheng, W., Highly Stretchy Black Gold E-Skin Nanopatches as Highly Sensitive Wearable Biomedical Sensors. Adv. Electron. Mater. 2015, 1 (4), 1400063.

95. $\quad$ Gong, S.; Schwalb, W.; Wang, Y.; Chen, Y.; Tang, Y.; Si, J.; Shirinzadeh, B.; Cheng, W., A wearable and highly sensitive pressure sensor with ultrathin gold nanowires. Nat. Commun. 2014, 5, 3132deffen.

96. Jason, N. N.; Ho, M. D.; Cheng, W., Resistive electronic skin. J. Mater. Chem. C 2017, 5 (24), 5845-5866.

97. Shi, G.; Araby, S.; Gibson, C. T.; Meng, Q.; Zhu, S.; Ma, J., Graphene Platelets and Their Polymer Composites: Fabrication, Structure, Properties, and Applications. Adv. Funct. Mater. 2018, 28 (19), 1706705.

98. Zhou, J.; Yu, H.; Xu, X.; Han, F.; Lubineau, G., Ultrasensitive, stretchable strain sensors based on fragmented carbon nanotube papers. ACS Appl. Mater. Interfaces 2017, 9 (5), 4835-4842.

99. Amjadi, M.; Kyung, K. U.; Park, I.; Sitti, M., Stretchable, Skin-Mountable, and Wearable Strain Sensors and Their Potential Applications: A Review. Adv. Funct. Mater. 2016, 26 (11), 1678-1698.

100. Yang, H.; Leow, W. R.; Chen, X., 3D Printing of Flexible Electronic Devices. Small Methods 2018, 2 (1), 1700259.

101. Yang, T.; Xie, D.; Li, Z.; Zhu, H., Recent advances in wearable tactile sensors: Materials, sensing mechanisms, and device performance. Mater. Sci. Eng. R Rep. 2017, 115, 1-37.

102. Stassi, S.; Cauda, V.; Canavese, G.; Pirri, C., Flexible tactile sensing based on piezoresistive composites: A review. Sensors 2014, 14 (3), 5296-5332.

103. Zulkarnain, M.; Mariatti, M.; Azid, I., Effects of hybrid fillers based on micro-and nano-sized silver particles on the electrical performance of epoxy composites. J. Mater. Sci.: Mater. Electron. 2013, 24 (5), 1523-1529.

104. Park, J.-M.; Kwon, D.-J.; Wang, Z.-J.; Gu, G.-Y.; DeVries, K. L., Interfacial, fire retardancy, and thermal stability evaluation of graphite oxide (GO)-phenolic composites with different GO particle sizes. Compos. B Eng. 2013, 53, $290-296$.

105. Chen, S.; Wei, Y.; Wei, S.; Lin, Y.; Liu, L., Ultrasensitive Cracking-Assisted Strain Sensors Based on Silver Nanowires/Graphene Hybrid Particles. ACS Appl. Mater. Interfaces 2016, 8 (38), 25563-25570.

106. Shi, G.; Liu, T.; Kopecki, Z.; Cowin, A.; Lee, I.; Pai, J.-H.; Lowe, E. S.; Zhong, L. Y., A Multifunctional Wearable Device with a Graphene/Silver Nanowire Nanocomposite for Highly Sensitive Strain Sensing and Drug Delivery. C 2019, 5 (2), 17.

107. Bae, W. G.; Kim, D.; Kwak, M. K.; Ha, L.; Kang, S. M.; Suh, K. Y., Enhanced Skin Adhesive Patch with ModulusTunable Composite Micropillars. Adv. Healthcare Mater. 2013, 2 (1), 109-113.

108. Choi, M. K.; Park, O. K.; Choi, C.; Qiao, S.; Ghaffari, R.; Kim, J.; Lee, D. J.; Kim, M.; Hyun, W.; Kim, S. J., Cephalopod-Inspired Miniaturized Suction Cups for Smart Medical Skin. Adv. Healthcare Mater. 2016, 5 (1), $80-87$.

109. $\quad$ Armand, M.; Tarascon, J. M., Building better batteries. Nature 2008, 451, 652.

110. Yoshino, A., The Birth of the Lithium-Ion Battery. Angew. Chem. Int. Ed. 2012, 51 (24), 5798-5800.

111. Cheng, F.; Liang, J.; Tao, Z.; Chen, J., Functional Materials for Rechargeable Batteries. Adv. Mater. 2011, 23 (15), 1695-1715.

112. Izumi, A.; Sanada, M.; Furuichi, K.; Teraki, K.; Matsuda, T.; Hiramatsu, K.; Munakata, H.; Kanamura, K., Development of high capacity lithium-ion battery applying three-dimensionally patterned electrode. Electrochim. Acta 2012, 79, 218-222.

113. Ying, Y. H. In New generation 3D printed on-chip energy storage devices, 2016 IEEE International Conference on Electron Devices and Solid-State Circuits (EDSSC), 3-5 Aug. 2016; 2016; pp 472-475.

114. Zhang, F.; Wei, M.; Viswanathan, V. V.; Swart, B.; Shao, Y.; Wu, G.; Zhou, C., 3D printing technologies for electrochemical energy storage. Nano Energy 2017, 40, 418-431.

115. Tian, X.; Jin, J.; Yuan, S.; Chua, C. K.; Tor, S. B.; Zhou, K., Emerging 3D-Printed Electrochemical Energy Storage Devices: A Critical Review. Adv. Energy Mater. 2017, 7 (17), 1700127.

116. Spearing, S. M., Materials issues in microelectromechanical systems (MEMS). Acta Mater. 2000, 48 (1), $179-196$. 
117. Zhang, C.; Xu, J.; Ma, W.; Zheng, W., PCR microfluidic devices for DNA amplification. Biotechnol. Adv. 2006, 24 (3), 243-284.

118. Raccichini, R.; Varzi, A.; Passerini, S.; Scrosati, B., The role of graphene for electrochemical energy storage. Nat. Mater. 2014, 14, 271.

119. Wei, T.-S.; Ahn, B. Y.; Grotto, J.; Lewis, J. A., 3D Printing of Customized Li-Ion Batteries with Thick Electrodes. Adv. Mater. 2018, 30 (16), 1703027.

120. Choi, K.-H.; Ahn, D. B.; Lee, S.-Y., Current Status and Challenges in Printed Batteries: Toward Form Factor-Free, Monolithic Integrated Power Sources. ACS Energy Lett. 2018, 3 (1), 220-236.

121. Fan, F. R.; Tang, W.; Wang, Z. L., Flexible Nanogenerators for Energy Harvesting and Self-Powered Electronics. $A d v$. Mater. 2016, 28 (22), 4283-4305.

122. Wang, Z. L.; Chen, J.; Lin, L., Progress in triboelectric nanogenerators as a new energy technology and self-powered sensors. Energy Environ. Sci. 2015, 8 (8), 2250-2282.

123. Wang, Z. L.; Song, J., Piezoelectric Nanogenerators Based on Zinc Oxide Nanowire Arrays. Science 2006, 312 (5771), 242-246.

124. $\quad$ Fan, F.-R.; Tian, Z.-Q.; Lin Wang, Z., Flexible triboelectric generator. Nano Energy 2012, 1 (2), 328-334.

125. Wang, X., Piezoelectric nanogenerators-Harvesting ambient mechanical energy at the nanometer scale. Nano Energy 2012, 1 (1), 13-24.

126. Wang, Z. L., Triboelectric Nanogenerators as New Energy Technology for Self-Powered Systems and as Active Mechanical and Chemical Sensors. ACS Nano 2013, 7 (11), 9533-9557.

127. Seol, M. L.; Han, J. W.; Moon, D. I.; Yoon, K. J.; Hwang, C. S.; Meyyappan, M., All-printed triboelectric nanogenerator. Nano Energy 2018, 44, 82-88.

128. Chen, S.; Huang, T.; Zuo, H.; Qian, S.; Guo, Y.; Sun, L.; Lei, D.; Wu, Q.; Zhu, B.; He, C.; Mo, X.; Jeffries, E.; Yu, H.; You, Z., A Single Integrated 3D-Printing Process Customizes Elastic and Sustainable Triboelectric Nanogenerators for Wearable Electronics. Adv. Funct. Mater. 2018, 28 (46), 1805108.

129. Symes, M. D.; Kitson, P. J.; Yan, J.; Richmond, C. J.; Cooper, G. J.; Bowman, R. W.; Vilbrandt, T.; Cronin, L., Integrated 3D-printed reactionware for chemical synthesis and analysis. Nat. Chem. 2012, 4 (5), 349-354.

130. Deffenbaugh, P. I.; Newton, M.; Church, K. H. In Digital Manufacturing for Electrically Functional Satlet Structures, International Symposium on Microelectronics, International Microelectronics Assembly and Packaging Society: 2015; pp 000210000215.

131. McOwen, D. W.; Xu, S.; Gong, Y.; Wen, Y.; Godbey, G. L.; Gritton, J. E.; Hamann, T. R.; Dai, J.; Hitz, G. T.; Hu, L., 3D-Printing Electrolytes for Solid-State Batteries. Adv. Mater. 2018, 30 (18), 1707132. 
TOC

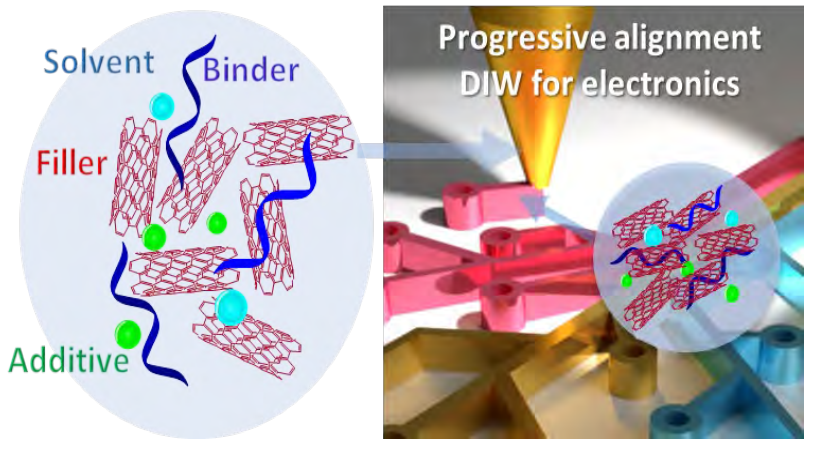

